\title{
Robust information routing by dorsal subiculum neurons
}

\author{
Takuma Kitanishi, Ryoko Umaba, Kenji Mizuseki
}

\begin{tabular}{|c|c|}
\hline Citation & Science Advances. 7(11); eabf1913 \\
\hline Issue Date & $2021-03-10$ \\
\hline Type & Journal Article \\
\hline Textversion & Publisher \\
\hline Highlights & 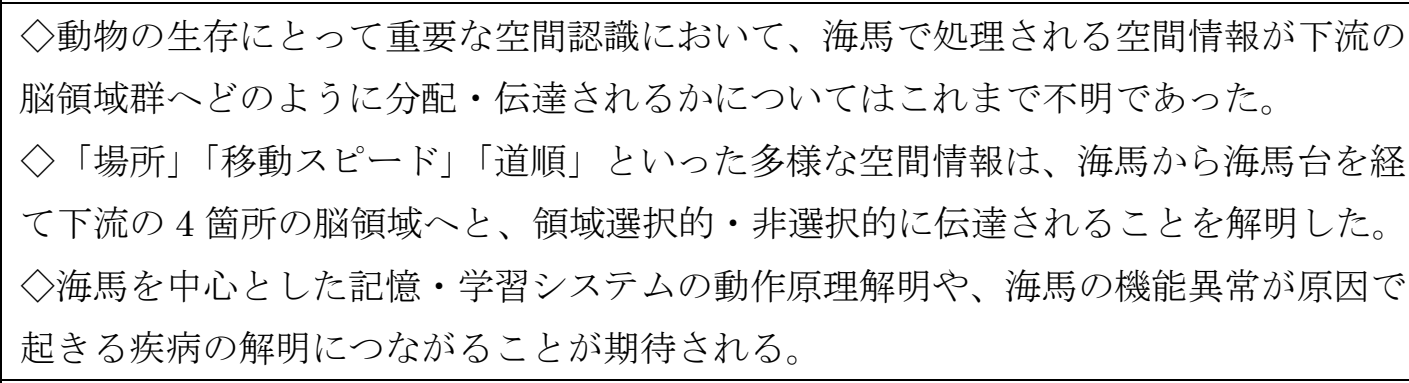 \\
\hline Rights & $\begin{array}{l}\text { (c) } 2021 \text { The Authors. This is an open-access article distributed under the terms of } \\
\text { the Creative Commons Attribution-NonCommercial license, which permits use, } \\
\text { distribution, and reproduction in any medium, so long as the resultant use is not } \\
\text { for commercial advantage and provided the original work is properly cited. } \\
\text { https://creativecommons.org/licenses/by-nc/4.0/ }\end{array}$ \\
\hline DOI & 10.1126/sciadv.abf1913 \\
\hline Supplementary & Supplementary material for this article is available at \\
\hline Materials & http://advances.sciencemag.org/cgi/content/full/7/11/eabf1913/DC1. \\
\hline
\end{tabular}

Self-Archiving by Author(s)

Placed on: Osaka City University

Kitanishi, T., Umaba, R., \& Mizuseki, K. (2021). Robust information routing by dorsal subiculum neurons. Science Advances, 7(11), eabf1913. https://doi.org/10.1126/sciadv.abf1913 


\begin{tabular}{|c|c|}
\hline 概要 & $\begin{array}{l}\text { 研究グループは、さまざまな空間情報が海馬から海馬台を経て下流の } 4 \text { 箇所の脳領域 } \\
\text { （側坐核・視床・乳頭体・帯状皮質）へと分配される脳情報の流れを世界で初めて明ら } \\
\text { かにしました。 } \\
\text { 空間認識に関わる情報は海馬で処理され、海馬で処理された情報は他の脳領域へと伝 } \\
\text { 達され活用されることで脳機能を支えると考えられていますが、どのように分配・伝達 } \\
\text { されるかはこれまで不明でした。 } \\
\text { そこで本研究では、ラットの海馬台において、情報の伝達先を網羅的に同定しつつ神 } \\
\text { 経活動を計測する大規模電気生理学解析を行いました。その結果、海馬台は、海馬に比 } \\
\text { べてノイズに強い頑健な情報表現を持つことを見いだしました。さらに、移動スピード」 } \\
\text { と「道順」の情報はそれぞれ帯状皮質と側坐核に選択的に伝達され、「場所」の情報は側 } \\
\text { 坐核・視床・乳頭体・帯状皮質の } 4 \text { 領域に均等に分配されることを明らかにしました。 } \\
\text { これは、海馬台から下流の脳領域への情報分配の様式を明らかにした世界初の成果で、 } \\
\text { 海馬を中心とした記憶システムの動作原理の解明や、認知症における記憶力低下の病態 } \\
\text { の理解につながることが期待されます。 }\end{array}$ \\
\hline Description & 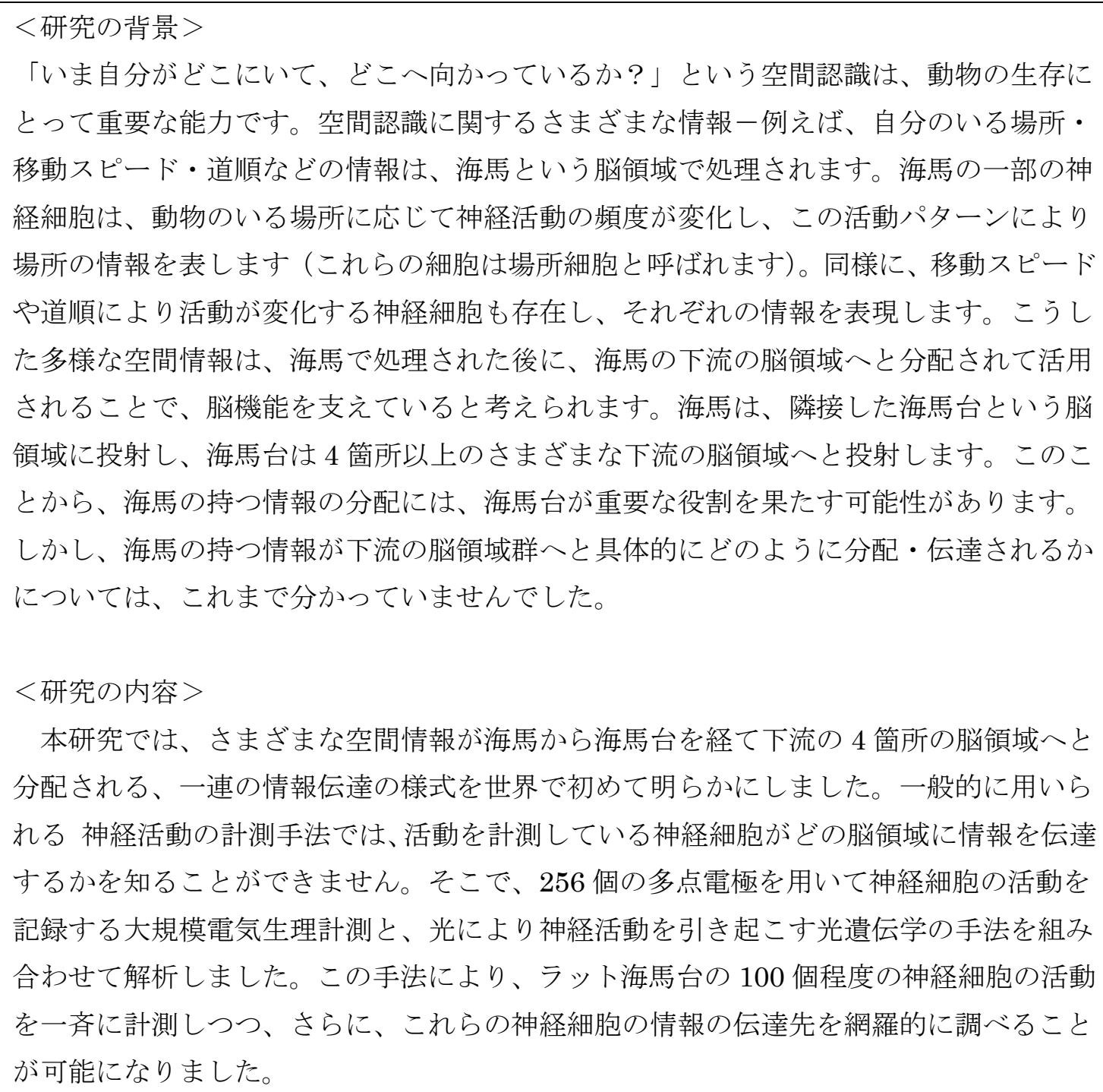 \\
\hline
\end{tabular}


この手法を用いて、ラットが空間探索の課題を行う際の海馬と海馬台の神経活動を収 集し、情報伝達の様式を調べました。その結果、主に 3 つの事柄を発見しました。

第一に、海馬台は海馬に比べて、ノイズに強い頑強な情報表現を持つことを見いだ し ました。海馬にはこれまでに知られていたように、場所細胞のような鋭い反応選択性を 示す神経細胞が多く存在しました。一方で、海馬台の神経細胞では一見したところ反応 選択性は緩いものの、神経活動の頻度が高いために海馬と同等の情報量を持ち、さらに 神経回路に生じるノイズの影響を受けにくいことが分かりました。この正確で頑強な情 報表現は、海馬台から長距離の神経投射を通じた下流の脳領域への情報伝達に適してい ると考えられます。

第二に、多様な 空間情報は海馬台から下流の脳領域群へと、領域選択的・非選択的に 伝達されることを見いだしました。具体的には、「移動スピード」と「道順」の情報はそ れぞれ帯状皮質と側坐核に選択的に伝達され、「場所」の情報は側坐核・視床・乳頭体・ 帯状皮質の 4 領域に均等に分配されることを明らかにしました。このことから、海馬台 が、情報の種類と標的脳領域に応じて、情報を分配・伝達する役割を持つことが分かり ました。

第三に、海馬台から下流の脳領域への情報伝達のタイミングは、ミリ秒の時間精度で 正確に制御されることを見いだしました。海馬や海馬台では、動物が活動しているとき やレム睡眠中にはシータ波、休んでいるときやノンレム睡眠中にはシャープウェーブ・ リップル波と呼ばれる脳波のリズムが発生します。海馬台から下流領域へと投射する神 経細胞は、標的とする脳領域によって、シータ波やシャープウェーブ・リップル波 のリ ズム に対して特定のタイミングで神経活動を生じたり、活動の頻度が変化したりするこ とが分かりました。

以上の結果から、多様な空間情報が海馬から海馬台を経て、下流の 4 領域へと分配さ れる一連の情報分配の様式を明らかにしました。

$<$ 今後の展開 $>$

海馬は、空間情報を含めたさまざまな情報を取り扱い、記憶・学習に重要な役割を果 たす脳領域であり、その機能低下は認知症の要因となります。今回の成果は、海馬を中 心とした記憶システムの動作原理の解明や、認知症における記憶力低下の病態の理解、 海馬 の機能異常が原因で起きる疾病の解明につながると期待できます。

“認知症などの病態解明に期待 世界初、空間認識を支える脳情報の流れを解明’.

大阪市立大学. https://www.osaka-cu.ac.jp/ja/news/2020/210311. (参照 2021-3-11) 


\section{Robust information routing by dorsal subiculum neurons}

\author{
Takuma Kitanishi ${ }^{1,2 *}$, Ryoko Umaba ${ }^{3}$, Kenji Mizuseki ${ }^{1 *}$
}

The dorsal hippocampus conveys various information associated with spatial navigation; however, how the information is distributed to multiple downstream areas remains unknown. We investigated this by identifying axonal projections using optogenetics during large-scale recordings from the rat subiculum, the major hippocampal output structure. Subicular neurons demonstrated a noise-resistant representation of place, speed, and trajectory, which was as accurate as or even more accurate than that of hippocampal CA1 neurons. Speed-and trajectory-dependent firings were most prominent in neurons projecting to the retrosplenial cortex and nucleus accumbens, respectively. Place-related firing was uniformly observed in neurons targeting the retrosplenial cortex, nucleus accumbens, anteroventral thalamus, and medial mammillary body. Theta oscillations and sharp-wave/ripples tightly controlled the firing of projection neurons in a target region-specific manner. In conclusion, the dorsal subiculum robustly routes diverse navigation-associated information to downstream areas.

\section{INTRODUCTION}

The hippocampus is crucially involved in spatial navigation and memory. Through interactions with intra- and extrahippocampal areas (1-7), hippocampal neurons diversely represent a variety of spatial navigation parameters, such as place (8), speed (9), trajectory (10-12), head direction $(9,13)$, and time $(14-16)$. The spike timing of these neurons is secured by multiple hippocampal neural oscillations, including theta oscillations, gamma oscillations, and sharpwave/ripples (SPW-Rs) (17-19), thus facilitating temporally precise information transmission within and between brain regions. To support navigational behavior output, hippocampal information is likely distributed to extrahippocampal areas. However, little is known about how diverse hippocampal information is distributed to downstream areas.

The subiculum (SUB) is the major hippocampal output structure, receiving hippocampal CA1 and entorhinal cortical output and projecting to various cortical/subcortical areas, including the nucleus accumbens (NAC), anteroventral thalamic nucleus (AV), interanteromedial thalamic nucleus (ITN), retrosplenial cortex (RSC), and medial mammillary body (MMB) (20). The CA1-SUB projection is topographically organized so that proximal and distal CA1 areas project to the distal (far from CA1) and proximal (close to CA1) SUB, respectively (20). The CA1 area shows graded spatial tuning along its proximodistal axis (21). In addition, SUB neurons located at proximal and distal areas innervate different target areas (22), suggesting that these projections potentially convey distinct information. Consistent with this idea, suppression of the proximal or distal SUB has a distinct impact on memory acquisition (23). Analogous to CA1 neurons, SUB neurons represent multiple variables associated with spatial navigation, such as place (24-26), axis (27), boundary (28), reward (29), and memory (30). Such anatomical and physiological evidence imply a pivotal role for the SUB in the distribution of multimodal information; however, little is known about the nature

${ }^{1}$ Department of Physiology, Osaka City University Graduate School of Medicine, Osaka 545-8585, Japan. ${ }^{2}$ PRESTO, Japan Science and Technology Agency (JST), Kawaguchi, Saitama 332-0012, Japan. ${ }^{3}$ Department of Neurosurgery, Osaka City University Graduate School of Medicine, Osaka 545-8585, Japan.

${ }^{*}$ Corresponding author. Email: kitanishi.takuma@med.osaka-cu.ac.jp (T.K.); mizuseki. kenji@med.osaka-cu.ac.jp (K.M.) of information distribution from this structure. An enigmatic point of subicular representation is that the overall subicular spatial firing is apparently dispersed $(24,25)$. Thus, it remains elusive whether the SUB fails to inherit the information content from the CA1 area or whether it inherits the information but converts it into a distinct form of representation suitable for interregional distribution to downstream areas. Moreover, it is unknown whether the SUB routes multiple types of information uniformly to all target areas or selectively routes distinct information to different targets. We anticipated that the SUB processes navigational information received from the CA1 area and routes the information to downstream targets in a projection-specific manner.

We investigated the above hypothesis by identifying axonal projections using optogenetics (31) while performing large-scale extracellular recordings $(32,33)$ of the rat dorsal SUB and CA1 area during multiple spatial tasks and sleep. We found that the SUB has a noise-resistant, accurate representation of multiple types of navigation-associated information and routes this information uniformly or selectively to target areas depending on the type of information.

\section{RESULTS}

\section{The SUB comprises projection neurons targeting distinct} downstream areas

Anterograde tracing revealed that the major projection targets of the rat dorsal SUB include the NAC, AV, anterodorsal thalamic nucleus, ITN, nucleus reuniens, RSC, and MMB (Fig. 1, A to E). A moderate projection was also observed in the dorsal tenia tecta and dorsal peduncular cortex (Fig. 1B). These projections were consistent with those reported by a previous study (22). Next, we determined the somata locations of SUB projection neurons by injecting the retrograde tracer cholera toxin $B$ subunit conjugated with Alexa Fluor 488 (CTB488) into one of the above target areas. In addition to the well-characterized differences between the proximal and distal SUB areas (22), we observed robust differences between the superficial and deep locations of SUB projection neurons (Fig. 1F and fig. S1) (34). Deeply located SUB neurons have been recently reported to have different gene expression patterns from other SUB neurons 

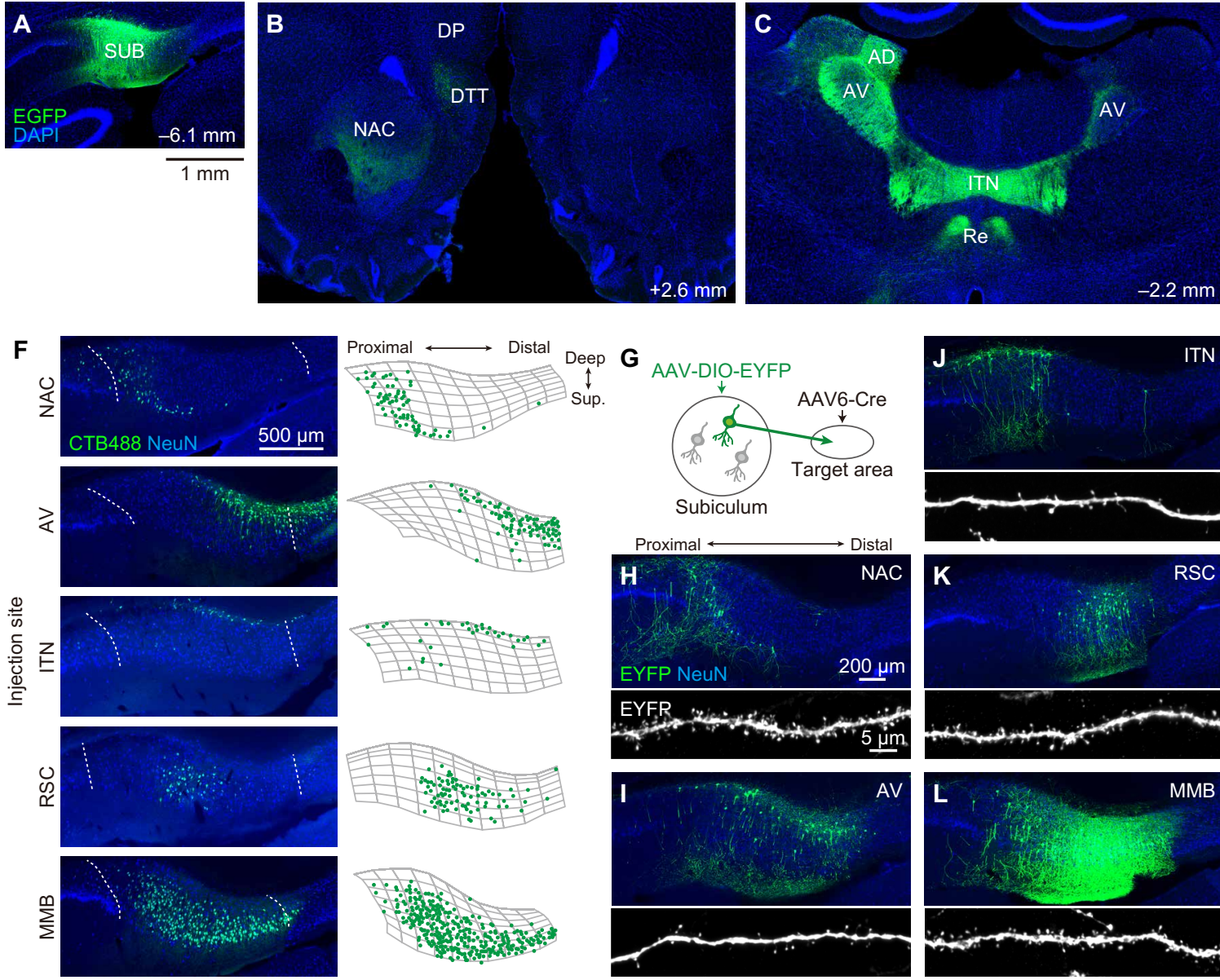

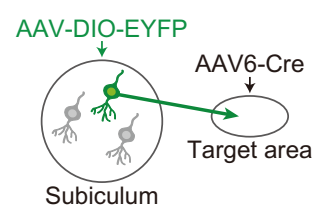

Proximal
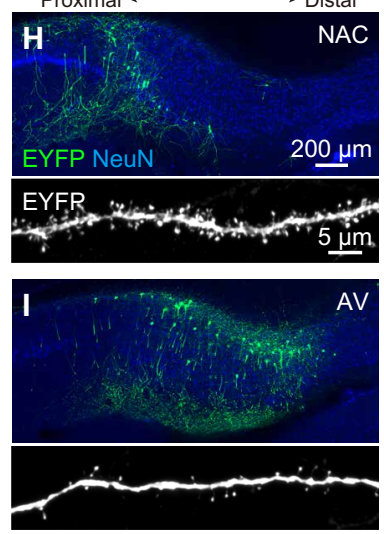
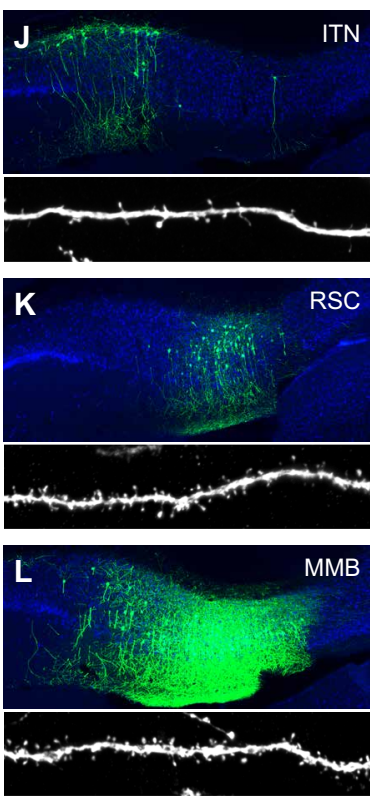
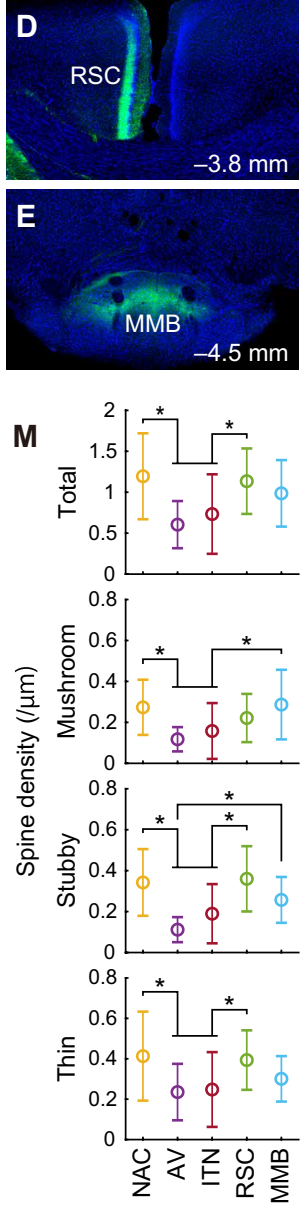

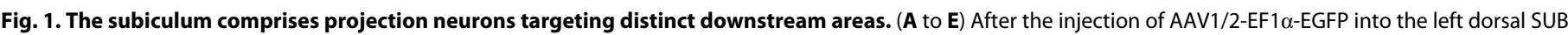

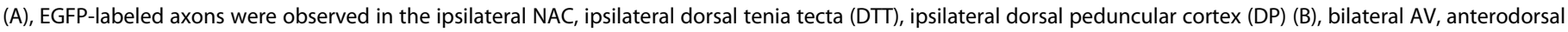

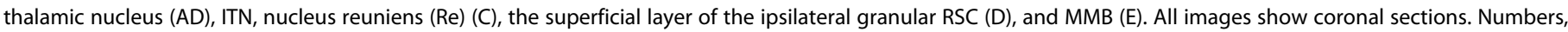

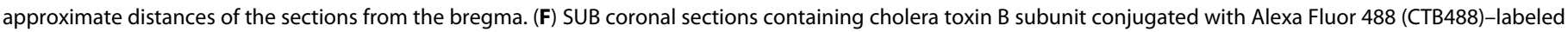

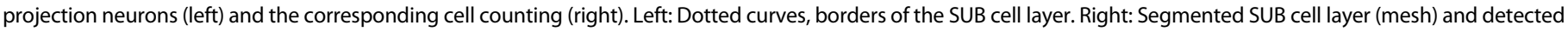

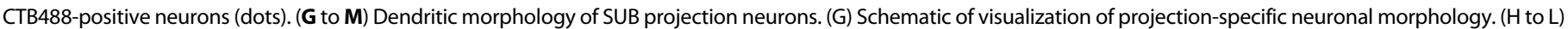

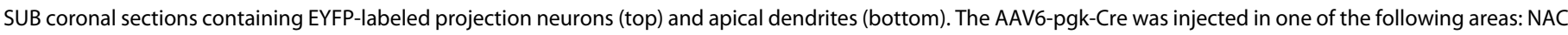

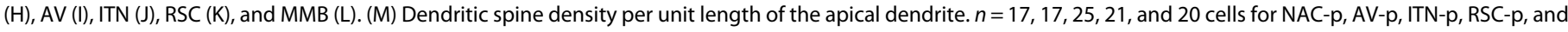
MMB-p SUB neurons, respectively. ${ }^{*} P<0.05$, Tukey test. Means \pm SD.

$(23,35)$. Projection-specific visualization of neuronal morphology (Fig. 1, G to L) revealed that dendritic spine density was lower in AVprojecting (AV-p) and ITN-projecting (ITN-p) neurons than in NACprojecting (NAC-p) and RSC-projecting (RSC-p) neurons (Fig. 1M). These results, together with accumulating previous evidence $(22,23,36)$, indicate that SUB projection neurons comprise at least partly separated groups of neurons that target distinct downstream areas.

\section{Optogenetic identification of projection targets}

The anatomical observations led us to hypothesize that SUB projection neurons convey distinct information depending on the projection targets. To investigate this, we combined large-scale extracellular recordings $(32,33)$ from the SUB and CA1 area of freely behaving rats with optogenetic identification of the projection targets (31) of the recorded SUB neurons (Fig. 2A). We stereotaxically introduced adeno-associated virus (AAV) expressing channelrhodopsin- 2 under the control of synapsin promoter, AAV1-hSyn-hChR2(H134R)-enhanced yellow fluorescent protein (EYFP), into the dorsal SUB, inserted a 256-channel silicon probe into the dorsal SUB and CA1 area, and implanted up to four optical fibers to each projection target (NAC, AV, RSC, and MMB) in each rat (Fig. 2, B to F, and fig. S2). We selected these four target areas because they were strongly innervated by the SUB (Fig. 1) while being anatomically distant from each other, which would maximize the anatomical specificity of optical simulation. Rats performed multiple spatial tasks, including an open-field, a linear-track, and an alternating T-maze task, and rested/slept in a small enclosure before and after the tasks. We monitored and analyzed a total of 315 and 319 putative principal cells in the CA1 and SUB, respectively, from 22 recording sessions in 11 rats (fig. S3, A to $\mathrm{C}$, and table $\mathrm{S} 1$ ).

To identify the projection targets of activity-monitored neurons with antidromic spikes (31), we irradiated blue light pulses sequentially to each target area during the rest sessions. In response to the light pulses, a proportion of SUB neurons generated short-latency 
A
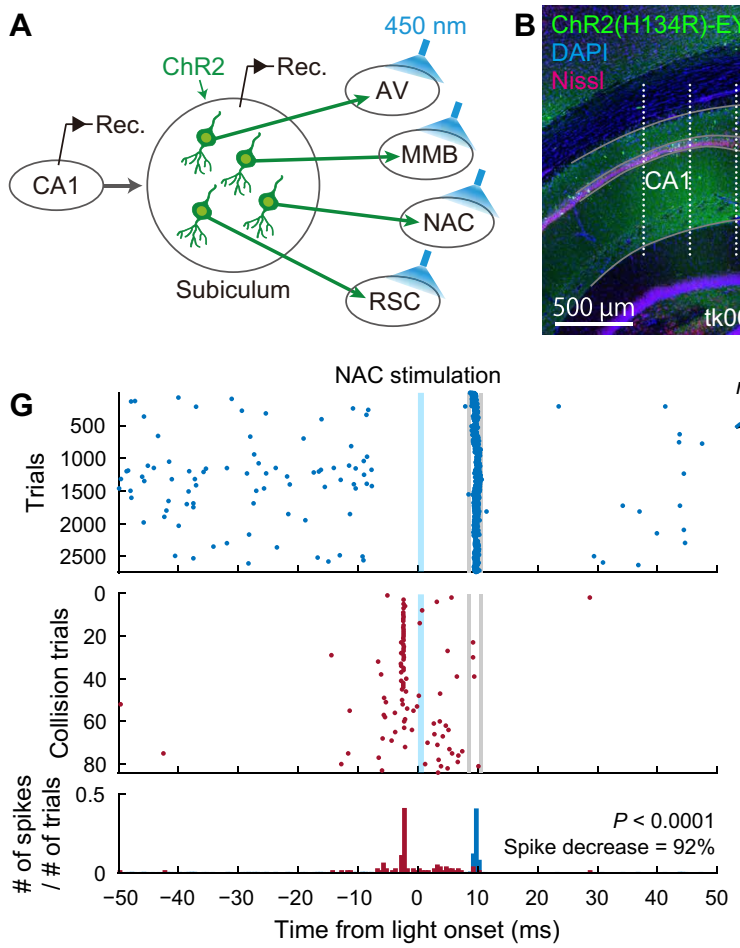
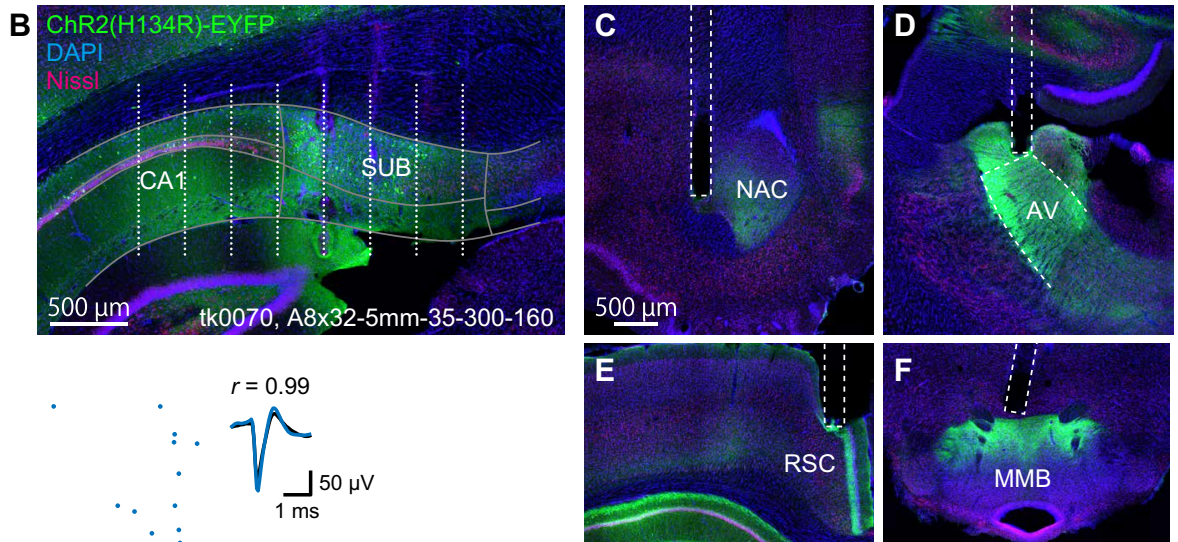

E

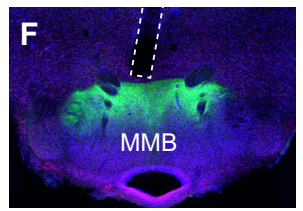

H

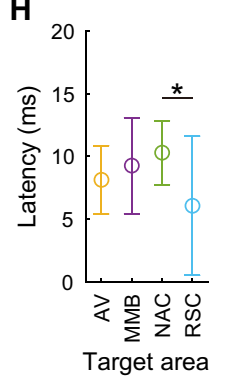

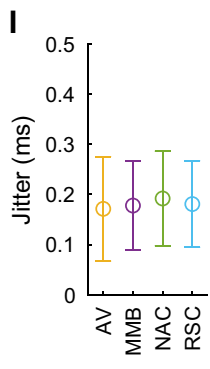
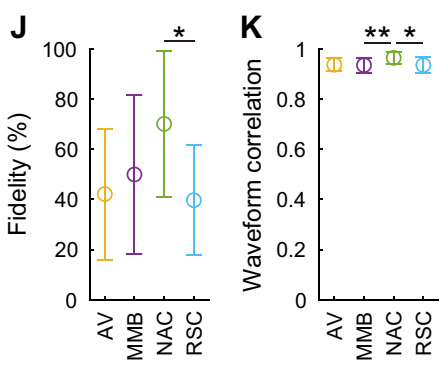

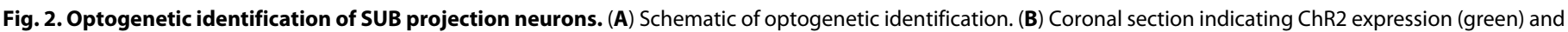

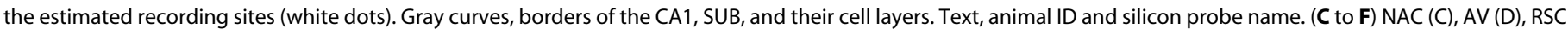

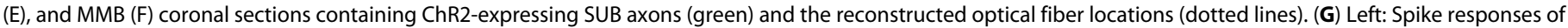

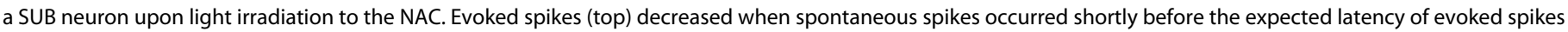

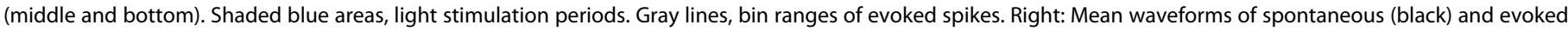

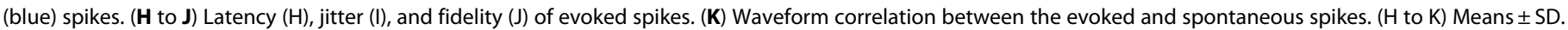
${ }^{*} P<0.05$ and ${ }^{*} P<0.01$, Tukey test.

( $<25 \mathrm{~ms} ; 8.7 \pm 4.0 \mathrm{~ms}$, means $\pm \mathrm{SD})$, low-jitter $(<0.5 \mathrm{~ms}, 0.18 \pm 0.09 \mathrm{~ms})$ spikes with high fidelity $(>20 \%, 51.8 \pm 30.2 \%)$, and these neurons were identified as projection neurons innervating the irradiated area (Fig. 2, G to K, and fig. S3D). The locations of the identified projection neurons in the SUB cell layer were consistent with the distribution of retrogradely labeled CTB488-positive neurons (fig. S3E). RSC-p neurons had a shorter latency than NAC-p neurons (Fig. $2 \mathrm{H}$ ), presumably reflecting differences in the anatomical distance between the SUB and these target areas. Among SUB principal cells, we identified $11 \mathrm{AV}-\mathrm{p}$ (3.4\% of SUB principal cells), $28 \mathrm{MMB}-\mathrm{p}$ (8.8\%), 18 NAC-p (5.6\%), and 16 RSC-p (5.0\%) SUB neurons (table S1). Previous anatomical studies demonstrated that moderate proportions of SUB neurons have collateral projections to more than one area with several combinations of target areas $(22,23,36,37)$. Consistently, several SUB neurons were identified as projecting to more than one area (fig. S3E).

\section{The SUB represents place information as accurately as the CA1, and subicular projection neurons uniformly carry this information}

The hippocampal CA1 area and the SUB contain spatially tuned cells that fire whenever animals move through particular places in an environment $(8,24-26)$. We compared place representation in CA1 and SUB neurons while rats were running on a linear track. While many CA1 neurons fired at specific places along the track, SUB neurons fired at broader locations (Fig. 3A). Rate maps of eastbound and westbound trials were uncorrelated both in the CA1 and SUB (CA1: $r=-0.03 \pm 0.46$, SUB: $r=-0.07 \pm 0.44 ; t_{414}=0.96, P=0.34$, CA1 versus SUB). This is consistent with the known directionality of place representation on a linear environment $(9,26)$. Per-spike spatial information, expressed by the $I_{\text {spike value, a measure of the }}$ spatial specificity of individual cells (38), was lower in SUB than in CA1 neurons (means \pm SD: CA1, $0.94 \pm 0.77$ bits/spike; SUB, $0.34 \pm 0.46$ bits/spike; $Z=9.73, P<0.0001$, Wilcoxon rank sum test; Fig. $3 \mathrm{~B}$ and fig. S4A). In contrast, SUB neurons had higher mean firing rates (during trials in the preferred direction; CA1, $3.7 \pm 5.4 \mathrm{~Hz}$; SUB, $9.8 \pm 12.9 \mathrm{~Hz} ; Z=7.78, P<0.0001$; Fig. $3 \mathrm{C}$ and fig. S4A) and peak firing rates (in the preferred direction; CA1, $9.3 \pm 9.0 \mathrm{~Hz}$; SUB, $17.1 \pm 17.0 \mathrm{~Hz} ; Z=5.83, P<0.0001$; Fig. $3 \mathrm{D})$ than $\mathrm{CA} 1$ neurons. Because of this high firing rate, per-second spatial information, $I_{\mathrm{sec}}$ (38), which is equal to $I_{\text {spike }}$ multiplied by the mean firing rate, was comparable between CA1 and SUB neurons (CA1, $1.43 \pm 1.69 \mathrm{bits} / \mathrm{s}$; SUB, $1.39 \pm 1.87$ bits $/ \mathrm{s} ; Z=0.98, P=0.33$; Fig. $3 \mathrm{E}$ and fig. S4A). Moreover, SUB and CA1 neurons showed similar mutual information (39) of firing rates and places (CA1, $0.26 \pm 0.17$ bits; SUB, $0.29 \pm 0.23$ bits; $Z=0.51, P=0.61$; Fig. $3 F)$. The mutual information correlated with $I_{\text {sec }}$ (CA1: $r=0.87, P<0.0001$; SUB: $r=0.84$, $P<0.0001)$ but not with $I_{\text {spike }}$ (CA1: $r=0.004, P=0.96$; SUB: $r=0.11, P=0.08)$. These results suggest that, despite the apparent decrease in spatial specificity shown by the lower $I_{\text {spike }}$ value, SUB 
A
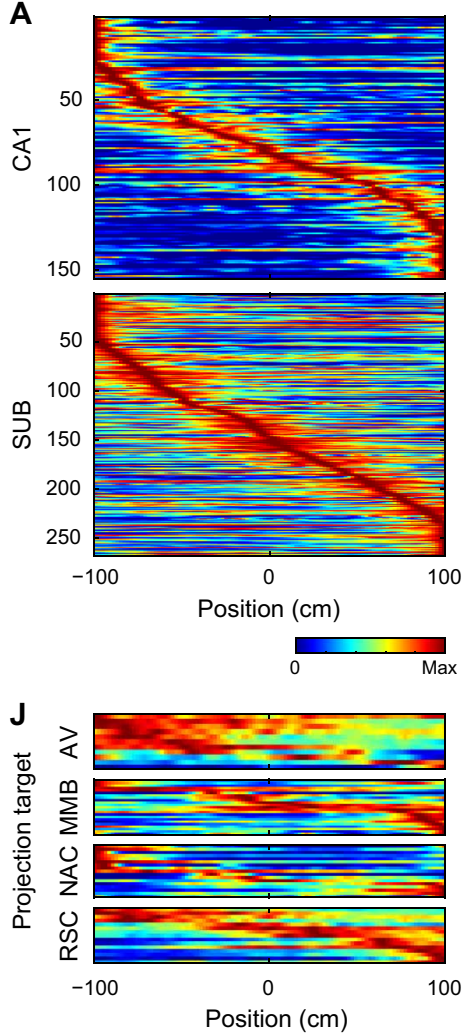
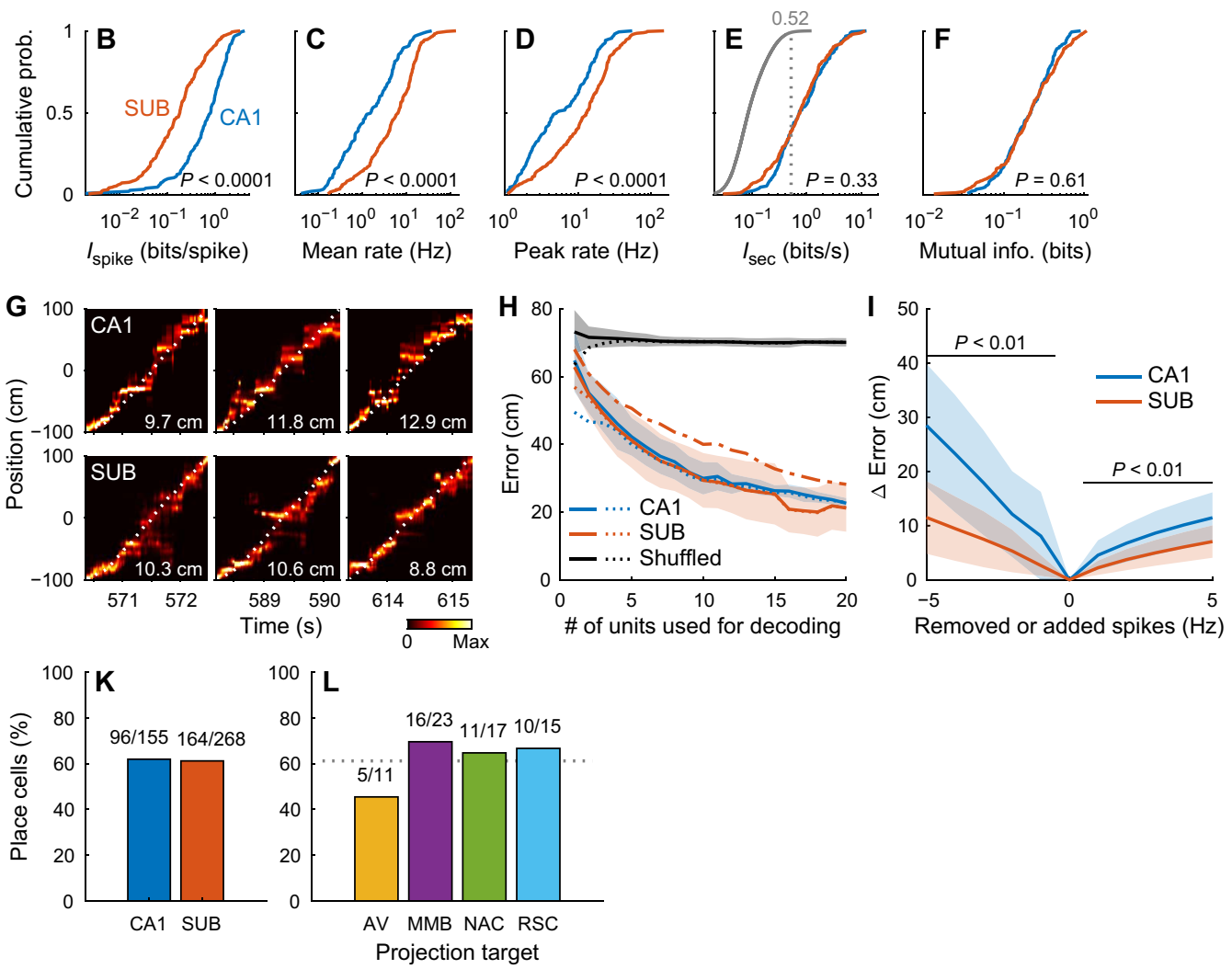

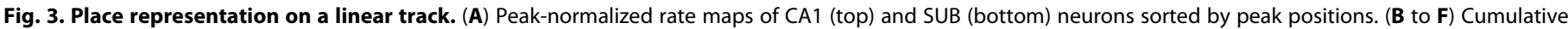

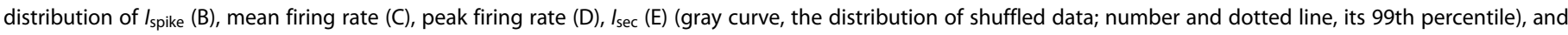

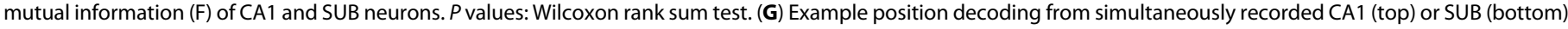

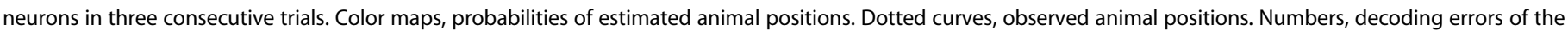

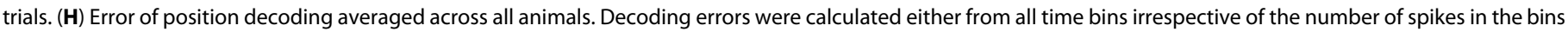

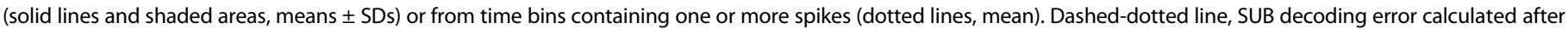

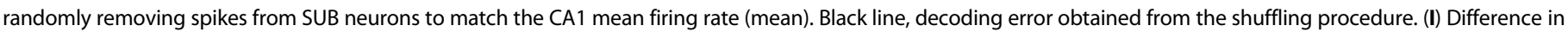

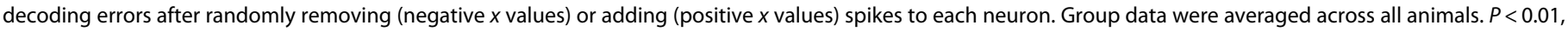

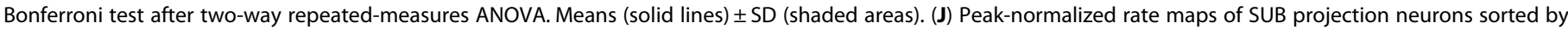

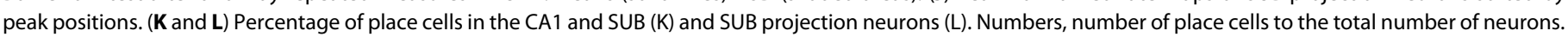
Dotted line, percentage of place cells in SUB neurons.

neurons convey a comparable amount of spatial information per unit time with that conveyed by CA1 neurons owing to the subicular high firing rate. The idea that SUB neurons robustly represent place information is further supported by the observation that their firing was anchored more to place than to the elapsed time from the start of trials (fig. S5, A to D) and by the fact that SUB rate maps were more temporally stable than the CA1 rate maps (fig. S5E).

Next, we investigated whether the SUB also represents place information as accurately as the CA1 at a cell population level using Bayesian decoding of animal position (Fig. 3, G and H) (40). The decoding errors obtained from CA1 and SUB neuronal populations were both smaller than those obtained using shuffled data, even when single neurons were used for decoding $(P<0.001$, Tukey test $)$, and became even smaller by increasing the number of neurons used $\left[F_{19,700}=90.87, P<0.001\right.$, two-way analysis of variance (ANOVA); Fig. $3 \mathrm{H}$, solid lines]. The decoding errors were comparable between the CA1 and SUB, irrespective of the number of neurons used ( $P>0.2$, Bonferroni test after two-way ANOVA; Fig. $3 \mathrm{H}$, solid lines), suggesting that CA1 and SUB neuronal populations of the same size convey a comparable amount of decodable spatial information. Randomly removing spikes from SUB neurons to match the mean firing rate of SUB neurons to that of CA1 neurons increased the decoding errors $\left(F_{1,917}=220.10, P<0.001\right.$; Fig. $3 \mathrm{H}$, dashed-dotted line), suggesting that the SUB high firing rate supports its accurate spatial representation.

To clarify how the spatial firing of single neurons relates to population coding, we estimated the contribution of single neurons to the decoding performance. The decoding improvement obtained by adding single units (see Materials and Methods) correlated with $I_{\mathrm{sec}}$ (CA1: $r=0.76, P<0.0001$; SUB: $r=0.69, P<0.0001$ ) and mutual information (CA1, $r=0.78, P<0.0001$; SUB, $r=0.73, P<0.0001$ ) but not with $I_{\text {spike }}$ (CA1, $r=0.06, P=0.46$; SUB, $r=0.04, P=0.40$ ) in both the CA1 and SUB, highlighting the tight association between $I_{\text {sec }}$ and population coding.

We hypothesized that the subicular representation gains robustness against noise owing to its high firing rate. We tested this idea by adding noise to the original spike trains before proceeding with the decoding analysis. In response to simple additive noise (41), we 
found a smaller increase in the decoding error in the SUB than in the CA1 (Fig. 3I), suggesting that population spatial coding in the SUB is more resistant to additive noise than that in the CA1.

Next, we asked how spatial information is conveyed by SUB projection neuron groups targeting distinct downstream areas (Fig. 3J). The proportions of place cells (defined by $I_{\mathrm{sec}}$ ) were similar in the CA1 and SUB $\left(\chi^{2}=0.02, P=0.88, \chi^{2}\right.$ test; Fig. $3 \mathrm{~K}$ and fig. S4A), as well as among the groups of SUB projection neurons targeting the $\mathrm{AV}, \mathrm{MMB}, \mathrm{NAC}$, or RSC $\left(\chi^{2}=1.99, P=0.57\right.$; Fig. $\left.3 \mathrm{~L}\right)$. Neither peak nor centroid positions of rate maps were significantly different among the four SUB projection neuron groups $(P>0.1$, Steel-Dwass test; Fig. 3J). These results suggest that the SUB projection neurons targeting these four downstream areas uniformly display place-related firing. The results for the spatial representation were consistent, irrespective of the sizes of a position bin and a time window, and were consistent across animals (fig. S6, A to K). We observed a similar spatial representation in a two-dimensional (2D) open field (figs. S4B and S7).
The SUB represents speed information more accurately than the CA1, and this information is most prominently conveyed by RSC-p neurons

The hippocampus contains neurons that respond to the running speed of animals (9). We thus investigated speed representation in CA1 and SUB neurons while rats foraged in an open field. Both the CA1 and SUB contained neurons with instantaneous firing rates that correlated with the rat's instantaneous running speed (Fig. 4A). To estimate the amount of speed information, as in the case of spatial information, we calculated per-spike speed information $I_{\text {spike }}$ and per-second speed information $I_{\text {sec }}(42)$. The $I_{\text {spike }}$ value was lower in SUB than in CA1 neurons (CA1, $0.054 \pm 0.057$ bits/spike; SUB, $0.028 \pm 0.059$ bits/spike; $Z=9.12, P<0.0001$, Wilcoxon rank sum test), while the mean firing rate of SUB neurons was higher than that of CA1 neurons (CA1, $1.5 \pm 1.9 \mathrm{~Hz}$; SUB, $5.6 \pm 5.2 \mathrm{~Hz} ; Z=11.48$, $P<0.0001$ ) (Fig. 4, B and C, fig. S4C). Consequently, the $I_{\text {sec }}$ value was similar between all CA1 and SUB neurons (CA1, $0.046 \pm 0.052$ bits/s;
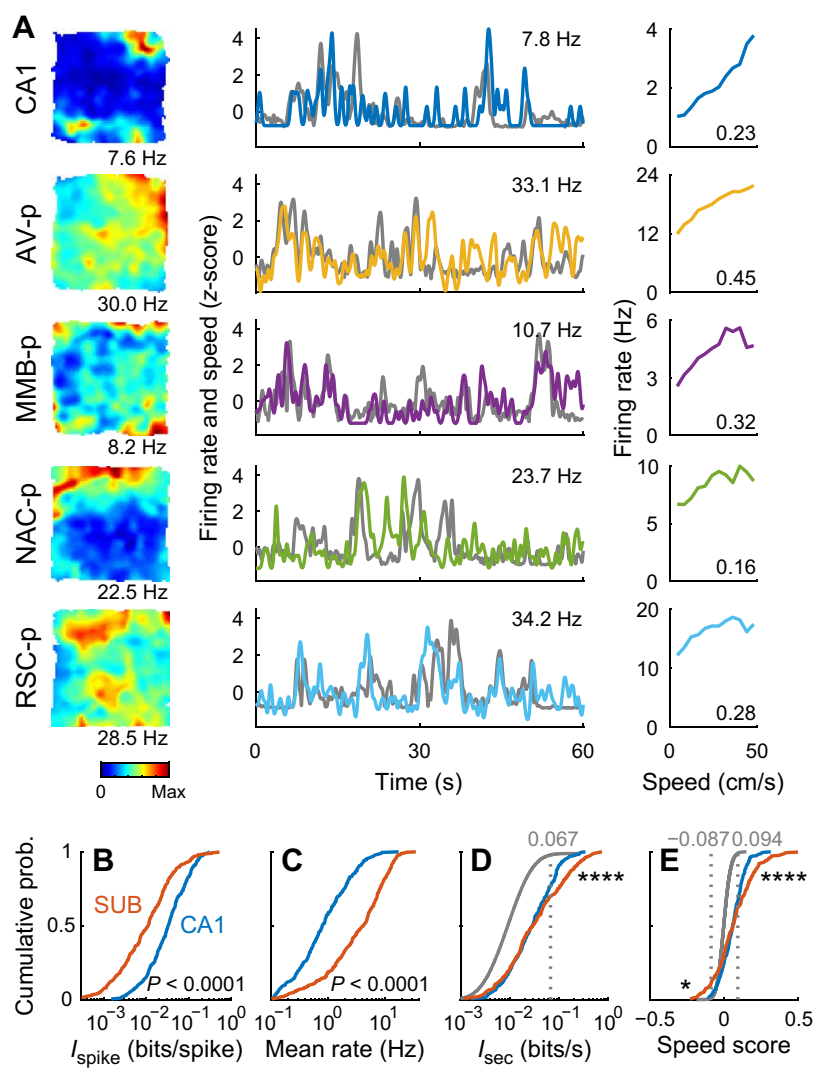
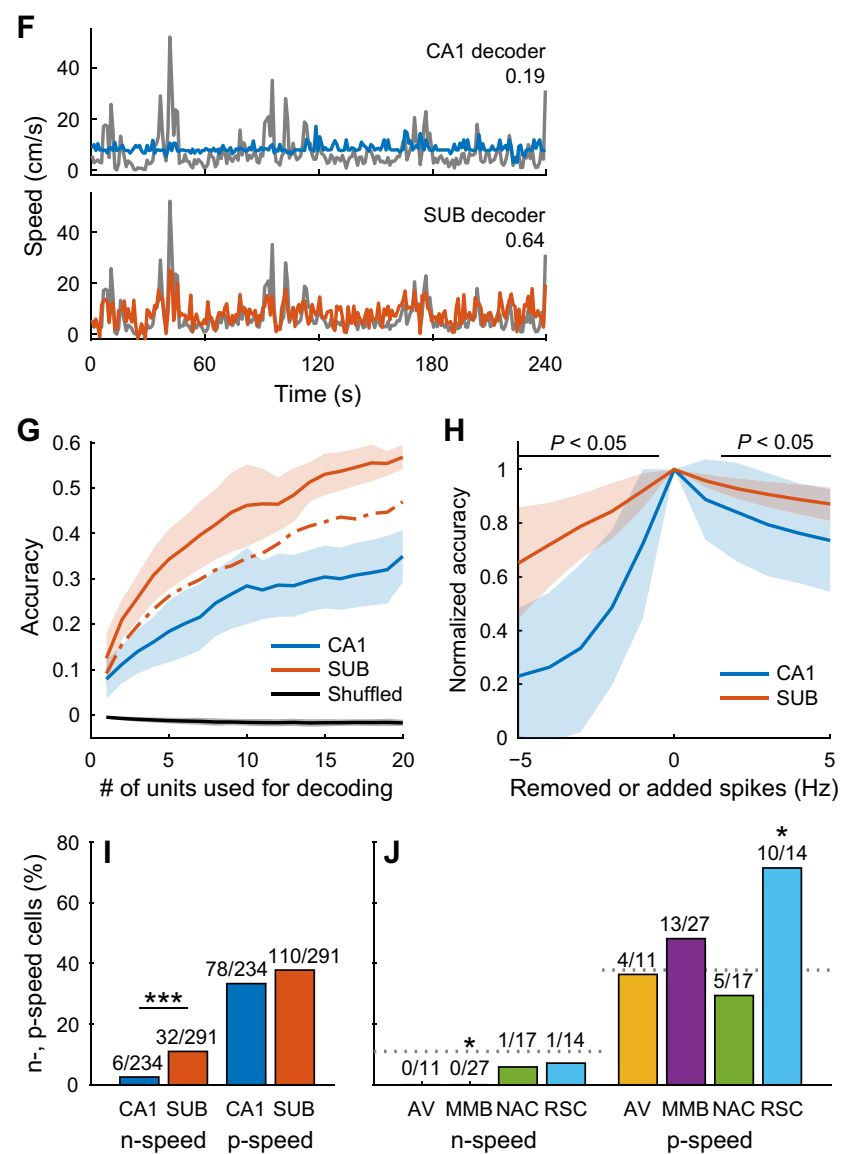

Fig. 4. Speed representation in an open field. (A) Rate maps (left), $z$-scored running speed (gray) and firing rate (color) (middle), and mean firing rate as a function of running speed (right). Each row shows the firing patterns of a single neuron. Numbers, peak firing rates in the figure (left and middle) and speed scores (right). (B to E) Cumulative distribution of $I_{\text {spike }}(B)$, mean firing rates (C), $I_{\text {sec }}(D)$, and speed scores (E). $P$ values: Wilcoxon rank sum test. (D and E) Gray curves, numbers, and dotted lines, the distribution of shuffled data and its 1 st $(E)$ and 99 th ( $D$ and $E$ ) percentiles. ${ }^{*} P=0.019$ and ${ }^{* * * *} P<0.0001, C A 1$ versus SUB neurons exceeding either the 1 st or 99 th percentile threshold, Wilcoxon rank sum test. (F) Example decoding of speed from simultaneously recorded CA1 (top) and SUB (bottom) neuron activity. Gray, observed speed. Color, decoded speed. Numbers, decoding accuracy. (G) Decoding accuracy averaged across all animals. Dashed-dotted line, SUB decoding accuracy calculated after randomly removing spikes from SUB neurons to match the CA1 mean firing rate (mean). Black line, decoding error obtained from a shuffling procedure. (G and $H$ ) Means (solid lines) \pm SD (shaded areas). (H) Normalized decoding accuracy after randomly removing (negative $x$ values) or adding (positive $x$ values) spikes to each neuron. Group data were averaged across all animals. $P<0.05$, Bonferroni test after two-way repeated-measures ANOVA. (I and $\mathbf{J})$ Percentage of $\mathrm{n}$-speed (left) and $\mathrm{p}$-speed (right) cells in the CA1 and SUB (I) and among SUB projection neurons (J). Numbers, number of speed cells to the total number of neurons. (I) ${ }^{* * *} P=0.0002, \chi^{2}$ test. (J) Dotted lines, percentage of $n$-speed (left) and p-speed (right) cells in SUB neurons. ${ }^{*} P<0.05$, bootstrap analysis. 
SUB, $0.077 \pm 0.114$ bits/s; $Z=1.12, P=0.26$; Fig. $4 \mathrm{D}$ and fig. S4C). However, when comparing only neurons with an $I_{\text {sec }}$ value exceeding the 99th percentile of the shuffled data, the $I_{\mathrm{sec}}$ value was higher for SUB than for CA1 neurons (CA1, $0.118 \pm 0.060 \mathrm{bits} / \mathrm{s}$; SUB, $0.205 \pm 0.137$ bits $/ \mathrm{s} ; Z=5.19, P<0.0001$; Fig. $4 \mathrm{D})$. To distinguish positively and negatively modulated speed cells, we calculated the speed score (43). The absolute speed score was tightly correlated with $I_{\text {sec }}$ (CA1, $r=0.75, P<0.0001$; SUB, $\left.r=0.80, P<0.0001\right)$ but was only modestly correlated with $I_{\text {spike }}$ (CA1, $r=0.32, P<0.0001$; SUB, $r=0.32, P<0.0001)$. The speed score was higher for SUB than for CA1 neurons (CA1, $0.141 \pm 0.043$; SUB, $0.201 \pm 0.087 ; Z=5.74$, $P<0.0001$, Wilcoxon rank sum test) when comparing neurons with a speed score exceeding the 99th percentile of the shuffled data distribution (Fig. 4E). Conversely, the speed score was smaller for SUB than for CA1 neurons (CA1, $-0.100 \pm 0.006$; SUB, $-0.142 \pm 0.041$; $Z=2.34, P=0.019)$ when comparing neurons with a speed score smaller than the first percentile of the shuffled data distribution (Fig. 4E). The speed scores obtained from the first and second halves of the sessions were positively correlated both for the CA1 and the SUB (CA1, $r=0.51, P<0.0001$; SUB, $r=0.79, P<0.0001$ ). These results suggest that, despite the broader speed tuning, as shown by the lower

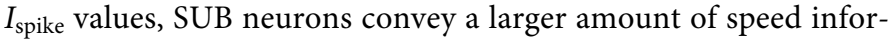
mation per unit time than that conveyed by CA1 neurons.

We asked whether the stronger speed representation in individual SUB neurons is reflected by the speed representation at the population level. To this end, we constructed a linear decoder of speed (Fig. 4, $\mathrm{F}$ and $\mathrm{G})$ (43). The decoding accuracy was higher in the SUB than in the CA1 irrespective of the number of neurons used $(P<0.05$, Bonferroni test after two-way ANOVA; Fig. $4 \mathrm{G}$ and fig. S6L). The SUB decoding accuracy decreased when spikes were randomly removed from $\mathrm{SUB}$ neurons to match the CA1 mean firing rate $(P<0.001$, Bonferroni test after two-way ANOVA; Fig. 4G, dasheddotted line); however, it was still higher than the CA1 decoding accuracy $(P<0.001)$. The single-unit decoding accuracy better correlated with the $I_{\mathrm{sec}}$ (CA1: $r=0.68, P<0.0001$; SUB: $r=0.75$, $P<0.0001)$ than with the $I_{\text {spike }}(\mathrm{CA} 1: r=0.27, P<0.0001$; SUB: $r=0.28, P<0.0001)$ value both in the CA1 and SUB (CA1: $Z=5.85$, $P<0.0001$; SUB: $Z=8.03, P<0.0001$; test of the difference between two correlation coefficients). Speed decoding by the SUB was more resistant to additive noises than that by the CA1 (Fig. $4 \mathrm{H}$ and fig. S6L).

We then investigated the proportion of positively ( $\mathrm{p}$-speed cells) and negatively ( $\mathrm{n}$-speed cells) modulated speed cells (see Materials and Methods). While the proportion of $\mathrm{p}$-speed cells was similar between the SUB and CA1 $\left(\chi^{2}=1.12, P=0.29\right.$; Fig. $\left.4 \mathrm{I}\right)$, that of $n$-speed cells was higher in the SUB than in the CA1 $\left(\chi^{2}=13.71, P=0.0002\right.$; Fig. 4I and fig. S4C). The $I_{\text {sec }}$ value was higher in the p-speed SUB cells than in the n-speed SUB cells and p-speed CA1 cells ( $n$-speed cells, CA1, $0.062 \pm 0.037 \mathrm{bits} / \mathrm{s}, \mathrm{SUB}, 0.096 \pm 0.099 \mathrm{bits} / \mathrm{s}$; $\mathrm{p}$-speed cells, CA1, $0.086 \pm 0.066$ bits/s, SUB, $0.153 \pm 0.143$ bits $/ \mathrm{s} ; P<0.05$, SteelDwass test). The proportion of p-speed cells among RSC-p neurons was larger than that among the entire SUB cell population $(P<0.05$, bootstrap analysis; Fig. $4 \mathrm{~J})$, indicating that speed-dependent firing is most prominent in RSC-p neurons.

\section{The SUB represents trajectory information as accurately as the CA1, and this information is most prominently conveyed by NAC-p neurons}

Next, we investigated trajectory-dependent firing at the start point of an alternating T-maze task (Fig. 5A) (12). A fraction of CA1 and
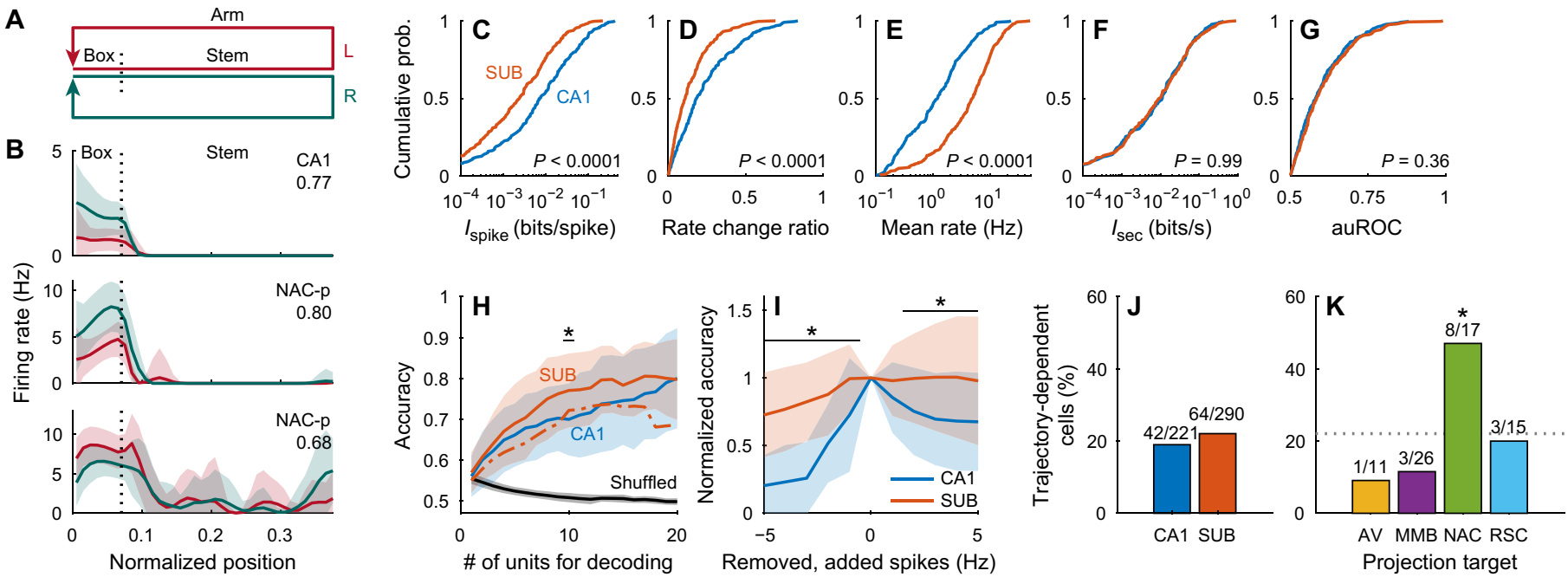

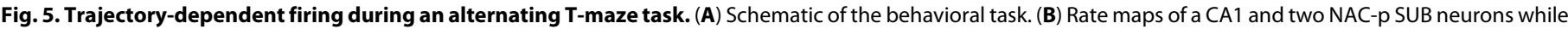

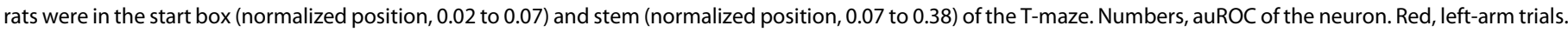

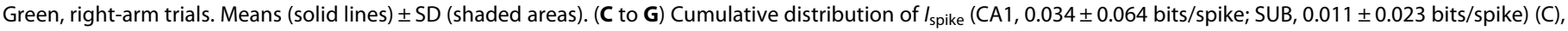

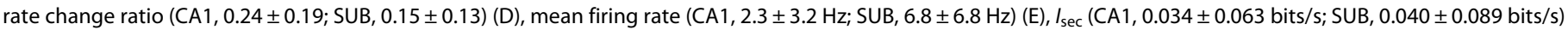

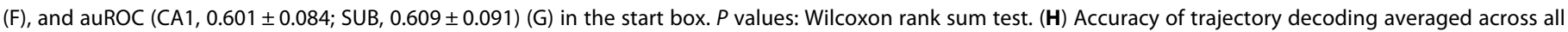

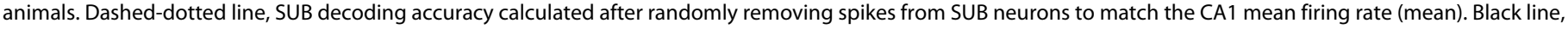

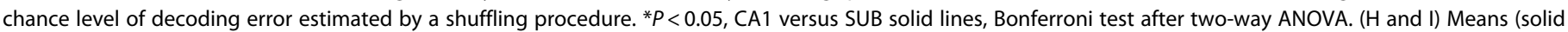

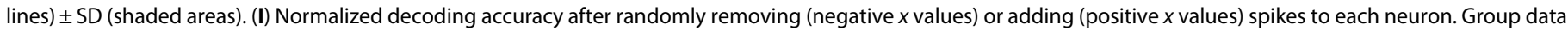

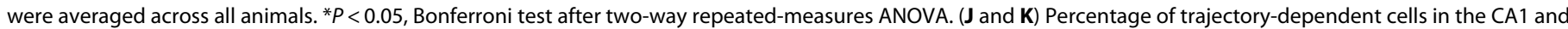

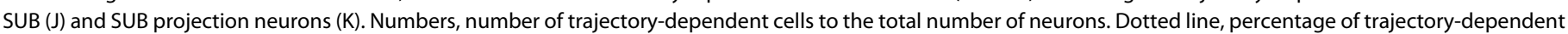
cells in SUB neurons. ${ }^{*} P<0.05$, bootstrap analysis. 
SUB neurons showed different firing rates in the start box according to the next choice of arm (Fig. 5B). To measure the information encoded regarding the next choice (left or right), as signaled by the firing rate in the start box, we defined the trajectory $I_{\text {spike }}$ and $I_{\text {sec }}$. Compared with CA1 neurons, SUB neurons showed lower $I_{\text {spike }}$ values $(Z=5.73, P<0.0001$, Wilcoxon rank sum test; Fig. 5C and fig. S4D) and a lower rate change ratio (see Materials and Methods, $Z=5.72$, $P<0.0001$; Fig. 5D). However, SUB neurons had a higher mean firing rate in the start box $(Z=10.16, P<0.0001$; Fig. $5 \mathrm{E}$ and fig. S4D $)$ and consequently had comparable $I_{\mathrm{sec}}$ values to those of CA1 neurons $(Z=0.02, P=0.99$; Fig. 5F and fig. S4D). In addition, the area under the receiver operating characteristic (auROC), indicating the goodness of fit of the binary classifier, was similar between CA1 and SUB neurons $(Z=0.92, P=0.36$; Fig. $5 \mathrm{G})$. We performed trajectory decoding from the firing rates in the start box, as described previously (5). SUB neurons showed moderately higher decoding accuracy than did CA1 neurons $\left(F_{1,432}=17.02, P<0.001\right.$; Fig. $5 \mathrm{H}$ and fig. S6M) and were more resistant to additive noise (Fig. 5I and fig. S6M). Random spike removal from SUB neurons to match the CA1 firing rate decreased the decoding accuracy $\left(F_{1,495}=46.36, P<0.001\right.$; Fig. 5H, dashed-dotted line).

Both the CA 1 and SUB contained $\sim 20 \%$ of trajectory-dependent cells $\left(\chi^{2}=0.72, P=0.40\right.$; Fig. 5J and fig. S4D). Among the groups of SUB projection neurons, NAC-p neurons contained a higher proportion of trajectory-dependent cells than the other groups of projection neurons $\left(\chi^{2}=9.06, P=0.03\right)$ and the entire population of SUB neurons $(P<0.05$, bootstrap analysis; Fig. $5 \mathrm{~K})$.

In the stem, only small proportions of cells showed trajectorydependent firing (CA1, 9.6\%; SUB, 7.7\%; $\chi^{2}=0.53, P=0.47$ ). This is consistent with a previous study demonstrating that CA1 neurons exhibit trajectory-dependent firing in the start box but not in the stem when a delay is introduced between trials (12).

\section{Weak head-direction tuning in subicular projection neurons}

Although neuronal firing associated with head direction emerges in the CA1 and SUB in cue-rich (13) and multipath environments (27), respectively, head-direction tuning is generally weak in both regions in non-cue-rich open fields $(25,27,44)$. Consistently, CA1 and SUB neurons displayed weak head-direction tuning in an open field (Fig. 6A). While per-spike directional information, $I_{\text {spike }}$ (CA1, $0.120 \pm 0.122$ bits/spike; SUB, $0.047 \pm 0.089$ bits/spike; $Z=11.55$, $P<0.0001$, Wilcoxon rank sum test; Fig. 6B and fig. S4E) and mean vector length (CA1, $0.134 \pm 0.095$; SUB, $0.078 \pm 0.076 ; Z=8.47$, $P<0.0001$; Fig. 6C) were higher in CA1 neurons than in SUB neurons, per-second directional information, $I_{\mathrm{sec}}$, was comparable between them (CA1, $0.081 \pm 0.058 \mathrm{bits} / \mathrm{s}$; SUB, $0.099 \pm 0.110 \mathrm{bits} / \mathrm{s}$; $Z=0.28, P=0.78$; Fig. $6 \mathrm{D}$ and fig. S4E). Bayesian decoding of head direction (45) revealed statistically significant $(P<0.001$, CA1 versus shuffled, SUB versus shuffled, Bonferroni test after two-way ANOVA) but marginal decoding performance for both CA1 and SUB neurons
A
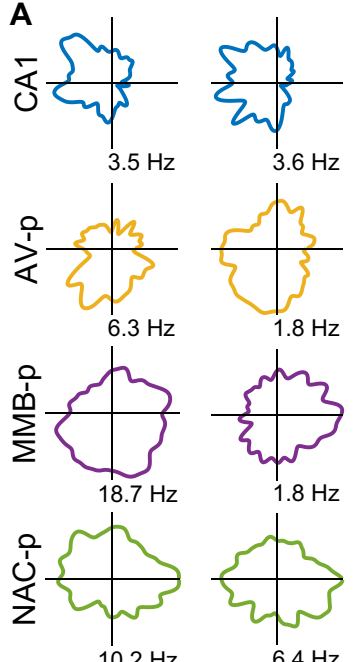

$6.4 \mathrm{~Hz}$
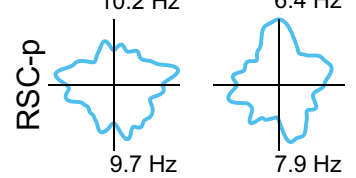

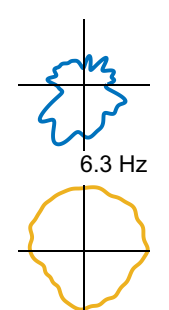

$16.6 \mathrm{~Hz}$
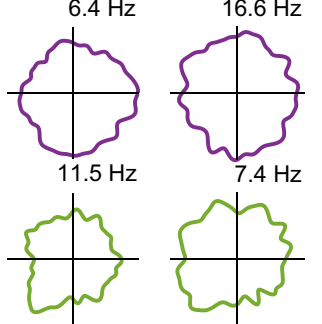

$9.8 \mathrm{~Hz}$
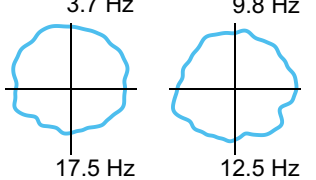
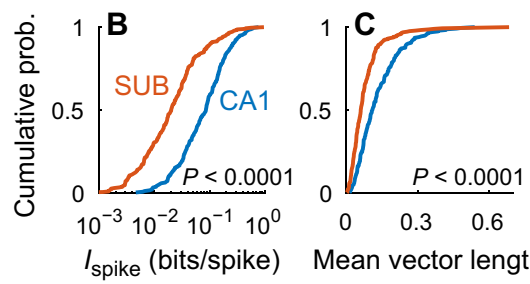

$I_{\text {spike }}$ (bits/spike) Mean vector length
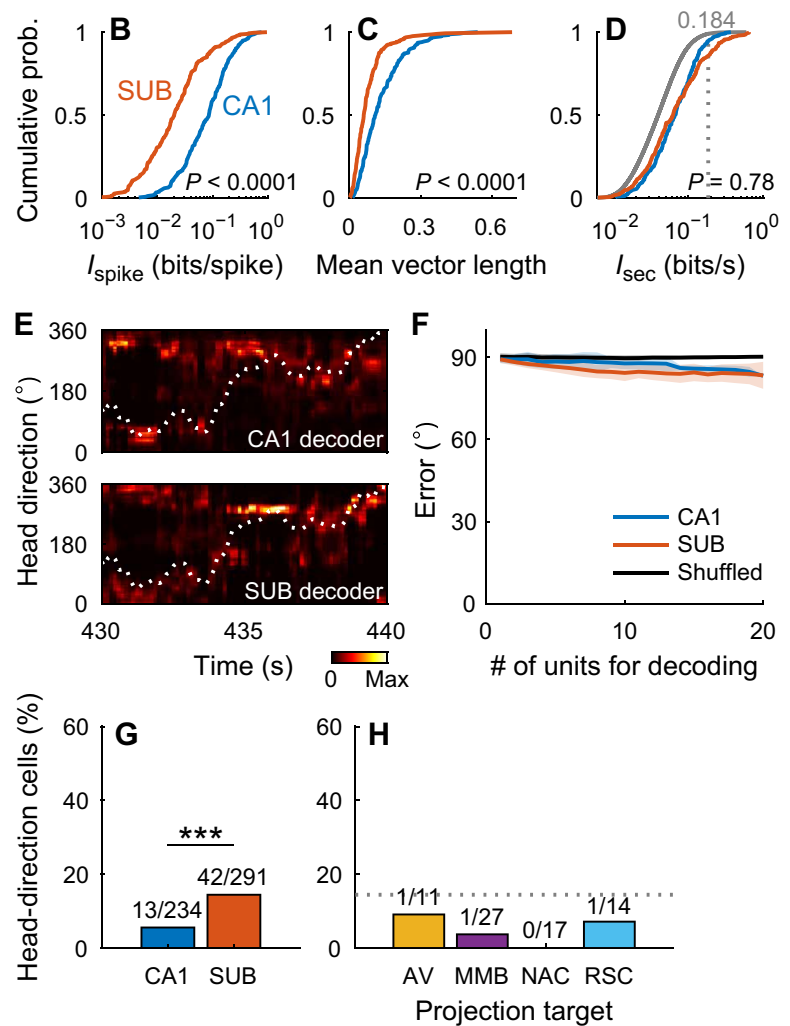

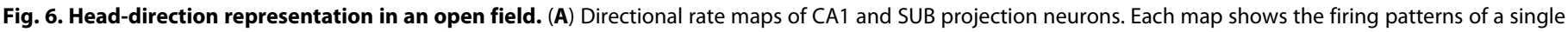

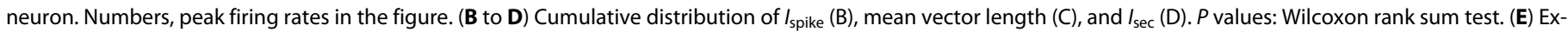

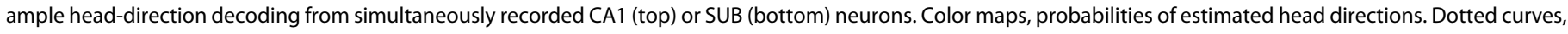

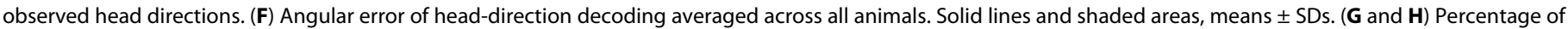

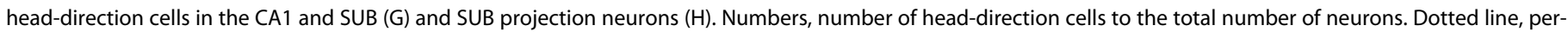
centage of head-direction cells in SUB neurons. ${ }^{* *} P=0.001, \chi^{2}$ test. 
(Fig. 6, E and F). While the proportion of head-direction cells was higher in the SUB than in the CA1 $\left(\chi^{2}=10.88, P=0.001\right.$; Fig. $6 \mathrm{G}$ and fig. S4E), all four groups of SUB projection neurons contained only small proportions of head-direction cells (Fig. $6 \mathrm{H}$ ).

\section{Projection-specific phase locking to theta oscillations}

Next, we asked whether the CA1, SUB, and SUB projection neurons have specific temporal firing patterns during theta oscillations. During running, we observed robust theta oscillations both in the CA1 and SUB (Fig. 7, A to C). Using theta oscillations at the center of the SUB cell layer as a reference (recording site location, $47 \pm 13 \%$ and $51 \pm 15 \%$ along proximal [0\%]-distal [100\%] and superficial [0\%]-deep [100\%] axes of the SUB cell layer, respectively), we examined theta phase locking of neuronal firing during RUN periods. Virtually, all CA1 and SUB neurons were significantly phase-locked $(P<0.05$, Rayleigh test) to subicular theta oscillations (CA1, 100\%; SUB, 99.0\%; Fig. 7D). The preferred theta phases of SUB neurons were at earlier phases of theta cycles than those of CA1 neurons $\left(\mathrm{CA} 1,46.1 \pm 45.4^{\circ}\right.$; SUB, $332.6 \pm 54.7^{\circ}$; circular mean \pm angular deviation; $U^{2}=4.30, P<0.001$, Watson $U^{2}$ test; Fig. $7, \mathrm{D}$ and $\mathrm{E}$, and fig. $\mathrm{S} 4 \mathrm{~F})$. We measured the strength of phase locking using pairwise phase consistency (PPC) (46). While CA1 neurons locked to the ascending phase of theta oscillations showed higher PPC than those locked to the descending phase $\left(F_{9,267}=4.80, P<0.0001\right.$, one-way ANOVA), SUB neurons locked to the peaks of theta oscillations showed higher PPC than those locked to troughs $\left(F_{9,290}=2.69\right.$, $P=0.005$ ) (Fig. 7D). For the entire population, PPC was modestly smaller in the SUB than in the CA1 (CA1, $0.060 \pm 0.058$; SUB, $0.052 \pm 0.065 ; Z=2.94 ; P=0.003$, Wilcoxon rank sum test).

SUB neurons had distinct preferred theta phases depending on the location of their somata. SUB neurons located at the distal-deep part (distal two-thirds and deep one-third of the cell layer) of the SUB cell layer fired at the earliest phases of theta cycles $\left(285.4 \pm 63.2^{\circ}\right)$, followed by neurons at the distal-superficial part (distal two-thirds and superficial two-thirds of the cell layer, $321.2 \pm 39.6^{\circ}$ ), and lastly neurons at the proximal part (proximal one-third of the cell layer, $9.6 \pm 54.8^{\circ}$; Fig. $7 \mathrm{~F}$ and fig. S4F). These three distributions of preferred theta phases were different from each other $(P<0.01$, Watson $U^{2}$ test with Bonferroni correction). In agreement with this locationdependent sequential firing, SUB projection neurons showed differences in theta phase locking (Fig. 7, G and H). The earliest preferred theta phases were observed in AV-p neurons $\left(250.8 \pm 50.0^{\circ}\right)$, followed by RSC-p neurons $\left(292.1 \pm 53.6^{\circ}\right)$, MMB-p neurons $\left(297.8 \pm 57.0^{\circ}\right)$, and lastly NAC-p neurons $\left(29.3 \pm 48.6^{\circ}\right)$. The preferred phases of NAC-p neurons were different from those of MMB-p, RSC-p, and AV-p neurons $\left(P<0.02\right.$, Watson $U^{2}$ test with Bonferroni correction). AV-p neurons were more strongly phase-locked to theta oscillations than RSC-p neurons $(t=2.64, P=0.041$, Steel-Dwass test; Fig. 7I). To assess which of the cell location and projection target better explain the preferred theta phases, we performed multiple regression analysis of preferred phases using the following six parameters as predictor variables: proximal-distal cell location, superficialdeep cell location, AV-p or not, MMB-p or not, NAC-p or not, and RSC-p or not (Fig. 7J). Among them, only the following four variables significantly predicted the preferred theta phase: proximaldistal location (standardized coefficient $\beta$ : $-0.30, P<0.001$ ), AV-p or not $(\beta:-0.20, P<0.001)$, MMB-p or not $(\beta:-0.23, P<0.001)$, and NAC-p or not $(\beta: 0.20, P=0.001)$, suggesting that preferred theta phase is conjunctively determined by these factors. These results demonstrate that theta oscillations robustly control the spike timing of SUB neurons in a target-specific manner. We observed similar patterns of theta phase locking during rapid eye movement (REM) sleep in both the CA1 and SUB (figs. S8 and S4F).

\section{Projection-specific firing modulation by SPW-Rs}

Next, we investigated the temporal firing patterns along SPW-Rs during slow-wave sleep (SWS). We observed synchronous SPW-Rs in the CA1 and SUB areas (Fig. 8, A and B). Using the ripple events detected at the center of the SUB cell layer as a reference, we examined the peri-ripple event firing rates of individual neurons. While most CA1 (92.7\%) and SUB (73.7\%) neurons showed significantly higher firing rates during ripple events than during baseline periods $(P<0.01, t$ test $)$, a small fraction of SUB neurons, but not of CA1 neurons, were significantly $(P<0.01, t$ test) suppressed during ripples (CA1, 0\%; SUB, 4.4\%; $\chi^{2}=14.11, P=0.0002$; Fig. 8, C and D) (47). These suppressed neurons were mostly localized in the distaldeep part of the SUB cell layer (proximal: $2.3 \%$, distal-superficial: $1.5 \%$, and distal-deep: $16.7 \% ; P<0.001$ by $\chi^{2}$ test; Fig. $8 \mathrm{E}$ and fig. $\mathrm{S} 4 \mathrm{G})$. Consistent with this location-dependent firing modulation, $73 \%$ of AV-p neurons were significantly suppressed during ripples, while only $18 \%$ of them were activated (Fig. 8 F). In contrast, nearly all MMB-p (93\%) and NAC-p (100\%) neurons were activated during ripples (Fig. $8 \mathrm{~F}$ ). RSC-p neurons comprised a mixture of activated (63\%) and suppressed (31\%) neurons (Fig. 8F). Consequently, AV-p neurons showed the lowest normalized peak height among all projection neuron groups, while RSC-p neurons showed a lower normalized peak height than did MMB-p neurons (Fig. 8G). The ripple-triggered activation/suppression was maintained regardless of the variations in ripple power $(P<0.01$ by Bonferroni test after two-way repeated-measures ANOVA, AV-p versus all other projection neuron groups, MMB-p versus RSC-p; $P=0.017$, NAC-p versus RSC-p; Fig. $8 \mathrm{H})$, duration $(P<0.01, A V-$ p versus all other projection neuron groups, MMB-p versus RSC-p; $P=0.024$, NAC-p versus RSC-p; Fig. 8I), or frequency $(P<0.01, A V-p$ versus all other projection neuron groups, MMB-p versus RSC-p; Fig. 8J). Essentially the same pattern of firing modulation was observed in SPW-Rs during the awake rest periods (figs. S4G and S9).

\section{DISCUSSION}

To the best of our knowledge, this is the first report demonstrating the pathway-specific information routing from the SUB. Three main findings were noted. First, SUB neurons robustly represented multiple types of navigation-associated information as accurately as or even more accurately than CA1 neurons. Second, depending on the type, the information was carried either uniformly or selectively by SUB projection neurons targeting distinct areas. Third, the firing of SUB projection neurons was distinctly controlled by theta oscillations and SPW-Rs in a target region-specific manner. These three findings address "how," "which," and "when" information is emitted from the SUB to downstream targets, respectively, providing a comprehensive view of information routing from the dorsal hippocampal formation.

A key feature of the subicular representations was that SUB neurons conveyed comparable (i.e., place and trajectory) or even greater (i.e., speed) information per unit time than that conveyed by CA1 neurons, despite their broader tuning. A previous study using a U-shaped track task suggested that SUB neurons carry more positional 

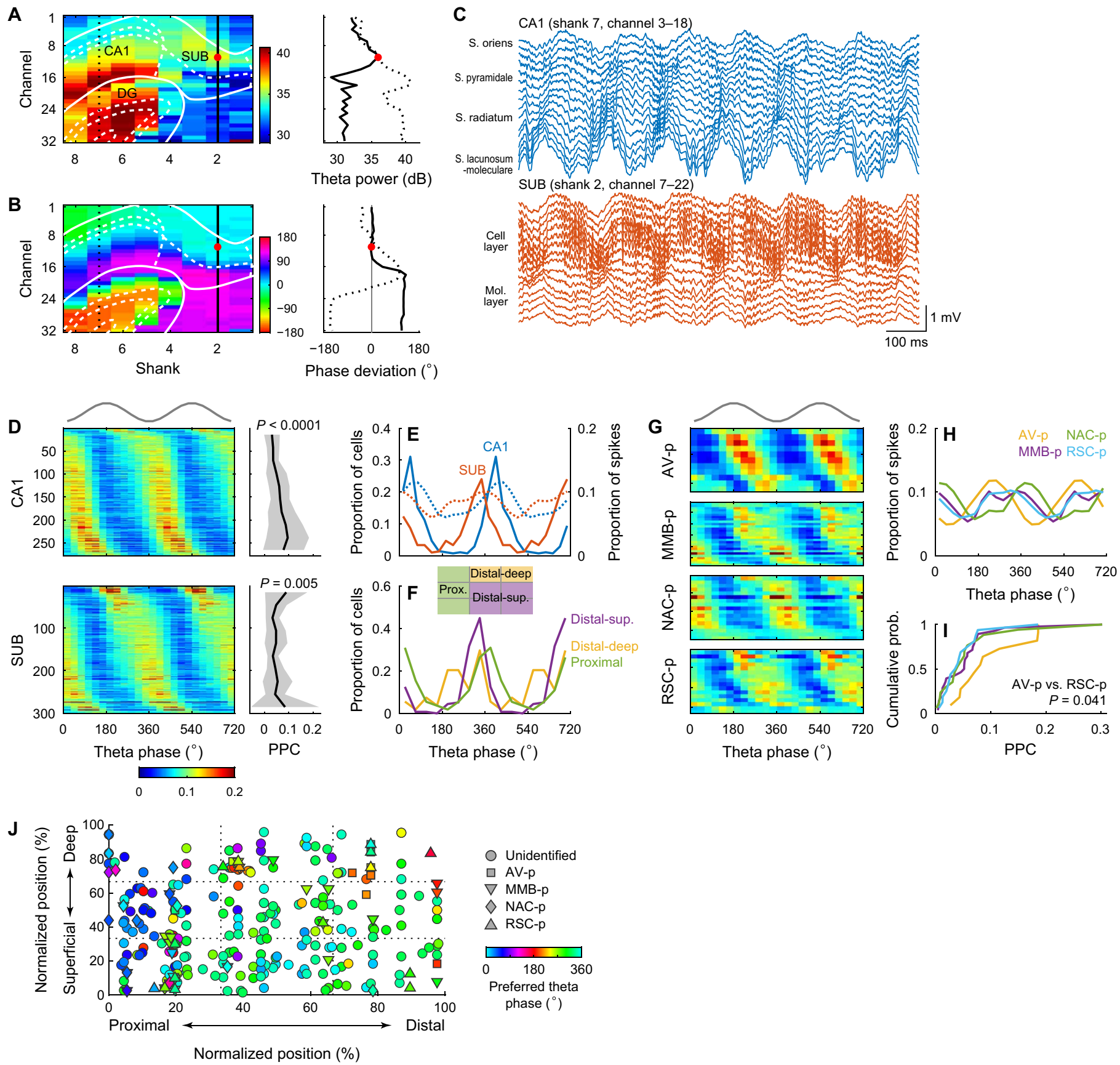

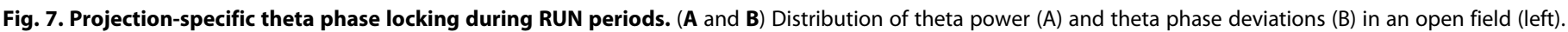

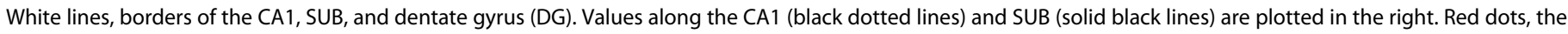

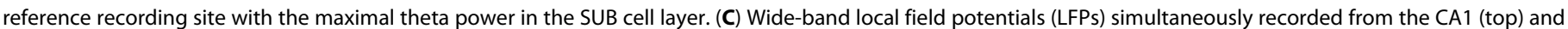

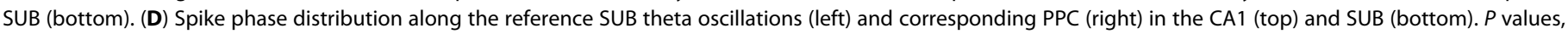

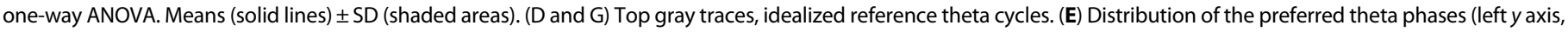

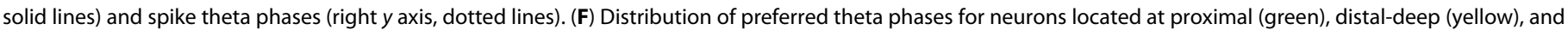

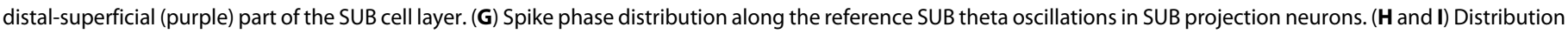

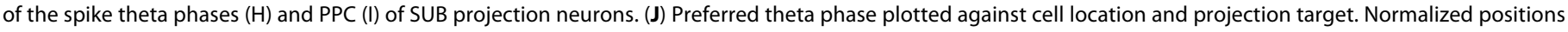
indicate the anatomical cell location within the SUB cell layer.

information per unit time than do CA1 neurons (26). They used model neurons derived from experimental data to estimate information content, partly because they could simultaneously record only a few SUB neurons. A limitation of their study is that it modeled neither bursting and history dependence in the spike trains $(48,49)$ nor transient synchrony between neurons (50), which is a hallmark of "cell assembly" (51). Such spike timing correlations both in single neurons and among multiple neurons are known to affect the amount 
A

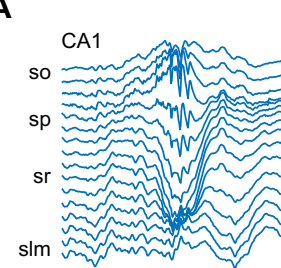

C
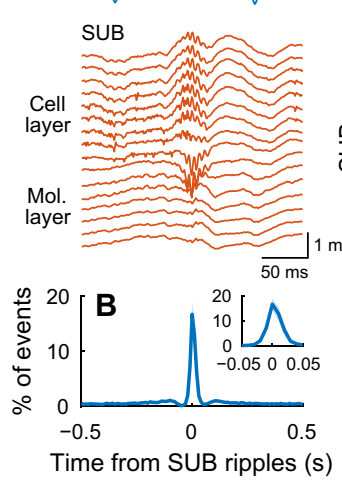
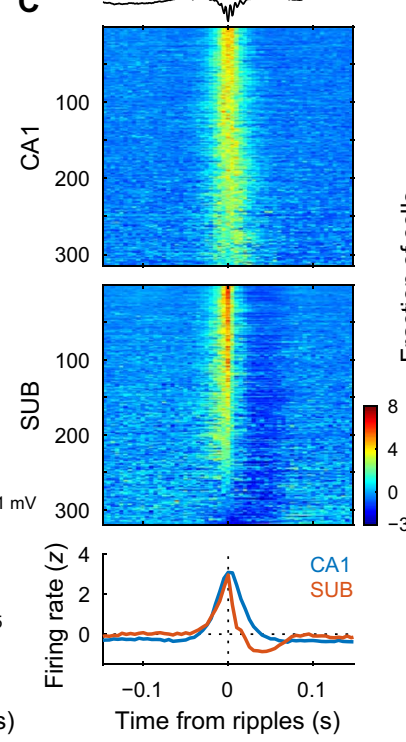
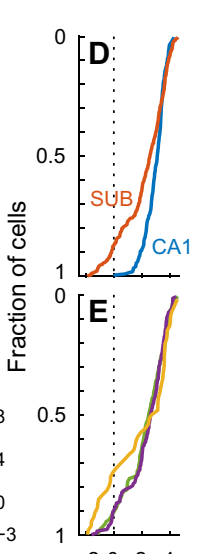

Peak height $(z)$
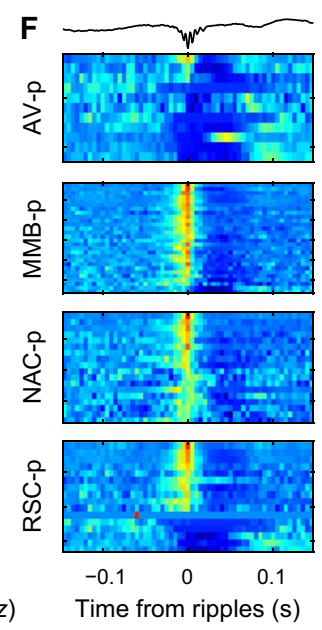

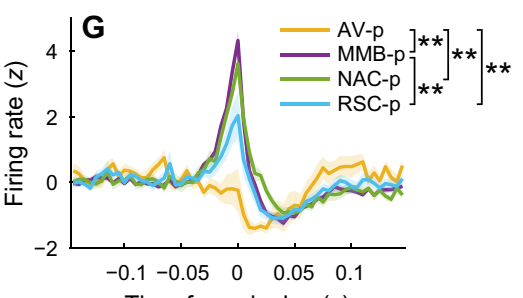

Time from ripples (s)

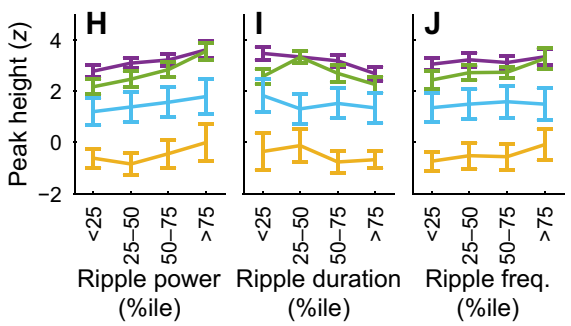

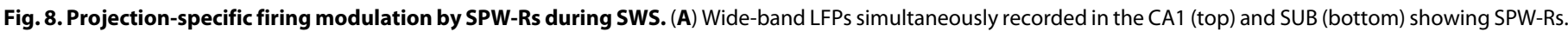

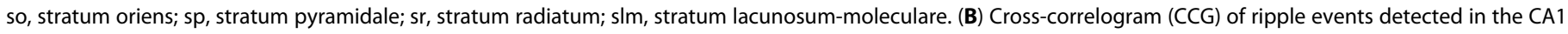

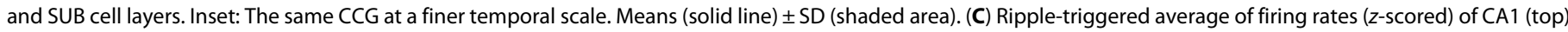

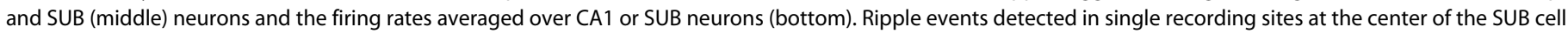

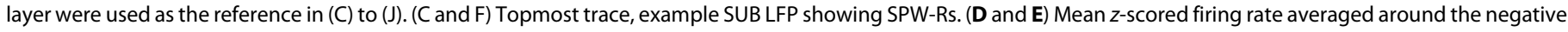

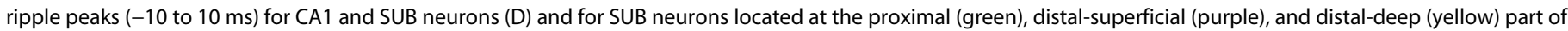

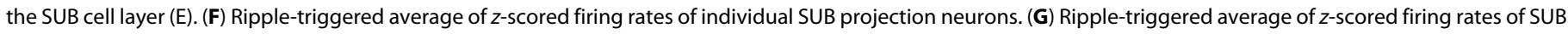

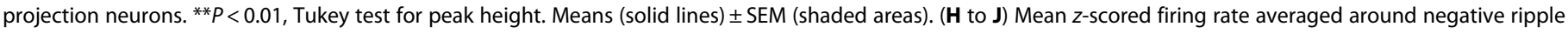
peaks (-10 to $10 \mathrm{~ms}$ ) as a function of ripple power $(\mathrm{H})$, ripple duration $(\mathrm{I})$, and ripple frequency $(\mathrm{J})$. The plot colors are the same as in $(\mathrm{G})$. Means $\pm \mathrm{SEM}$.

of information encoded (52). In contrast, we measured spatial information directly from the experimental data by simultaneously monitoring a larger number of SUB neurons using 256-channel silicon probes. Further, by using multiple behavioral tasks, we found that SUB neurons have accurate representations for speed and trajectory, which expands the concept of SUB place representation (26) to that of multiple navigation-associated variables.

Our results suggest that the sharply tuned, low-firing rate representation in the CA1 area is converted into a broadly tuned, highfiring rate representation in the SUB without losing the information content. This change in representation may be caused by the converging inputs onto single SUB neurons from multiple CA1 neurons, as proposed by previous studies $(24,25)$. In addition, the richer speed information in the SUB might be due to further convergence of entorhinal speed signals $(42,43)$. The high firing rate in the SUB is crucially important for supporting per-second information rate in single neurons, decoding performance as a population, and the noise-resistant robust coding, which may be suitable for long-range projections suffering from substantial noise (41). These coding strategies were common across place, speed, and trajectory information. Thus, we propose that a key role of the SUB is to generate noiseresistant, accurate representations for multiple types of navigationassociated information. The coding strategy of constructing such a high-firing rate, noise-resistant representation may apply not only for the SUB but also for the entire hippocampal circuit. The mean firing rates of principal cells progressively increase as they pass through the feed-forward network of the hippocampal formation (i.e., dentate gyrus $\rightarrow \mathrm{CA} 3 \rightarrow \mathrm{CA} 1 \rightarrow \mathrm{SUB})(24,53-55)$. Thus, one of the roles of the hippocampal circuit might be to convert the sparse firing in the dentate gyrus (55-58) to progressively denser and more robust representations.

We found that groups of SUB projection neurons uniformly (i.e., place) or selectively (i.e., speed and trajectory) carry information. Place information may be used in all target areas; in particular, the AV, MMB, and RSC are all implicated in spatial learning (59). As SUB neurons showed comparable spatial coding with CA1 neurons both at single-cell and population levels, we predict that SUB neurons projecting to regions other than the four that we identified also show strong place coding. Speed information prominently routed to the RSC may interact with visual-locomotion integration in this area $(60,61)$. Trajectory information routed to the NAC may help goal-directed action to obtain a reward, which is thought to be the major function of the NAC (62). Head-direction tuning was weak in all four groups of SUB projection neurons, suggesting that head-direction information in the AV (63) and RSC (64) is derived not from the SUB but from other regions innervating these areas. Considering that the ventral CA1 routes information related to anxiety, goal approach, and task engagement to distinct target areas, including the prefrontal cortex, amygdala, and NAC (31), the entire dorsoventral axis of the hippocampal formation might route distinct, relevant information to different target areas. Note that such discussion of functional allocations to different projections is based on the assumption that projection neurons sampled by optogenetics represent the neuronal population in the target pathways $(31,65)$. In addition, the information routed to downstream areas is not necessarily passed on to the neurons in the target areas. To precisely link the information routing to its network and behavioral functions, deliberate future studies would be necessary. For instance, whether 
the NAC-routed trajectory information is required for spatial working memory remains unknown. In line with our result, the disconnection of the SUB-NAC pathway has been shown to impair spatial working memory in a radial arm maze task but only when no delay was inserted between the training and test phases (66). In contrast, inactivation of the distal SUB, but not the proximal SUB containing NAC-p neurons, has been shown to impair spatial working memory in a Morris water maze task (23). In addition, Nelson et al. (67) found that the reciprocal connection between the SUB and anterior thalamic nuclei, including the AV, is required for a modified T-maze task, in which animals could not use intramaze cues. Collectively, while multiple SUB projections are recruited in spatial working memory tasks, their necessity appears to depend on various factors, including the type of behavioral task, task difficulty, delay length, and richness of available cues.

SUB projection neurons showed different preferred spike timing during theta oscillations, suggesting that distinct information is sent out sequentially to different target areas in each theta cycle. A potential determinant of the preferred spike timing is the topographically graded input from the entorhinal cortex. The medial and lateral entorhinal cortex (MEC and LEC, respectively) preferentially innervate the distal and proximal SUB, respectively (68). MEC layer 3 neurons, which project to the SUB (69), fire maximally around the peaks of theta oscillations measured in the CA1 pyramidal cell layer $(70,71)$, which matches the observed phase preference of distal SUB neurons. Therefore, the spike timing of distal SUB neurons during theta oscillations may be under strong control of MEC layer 3 inputs. By contrast, the LEC displays weaker theta oscillations/modulation (72). Thus, the theta phase preference of proximal SUB neurons may be mainly determined by CA1 inputs, which show a theta phase preference similar to that of proximal SUB neurons. All four downstream areas examined in this study exhibit theta-modulated activity, which is often coherent with hippocampal theta oscillations $(59,63,73,74)$. Thus, the SUB potentially coordinates theta-paced activity in multiple downstream areas with fine temporal precision. SUB projection neurons were also distinctly activated or suppressed during ripples. Because of the widespread projections of the SUB, precisely timed activity broadcasted from the SUB might organize the brain-wide activity (75) through the modulation of downstream areas $(47,74,76,77)$. Exactly how the routed information from the SUB is used in the target areas remains to be elucidated. Further studies are warranted to investigate the impact of SUB activity on information processing in downstream areas.

\section{MATERIALS AND METHODS}

All procedures of animal care and use were approved by the Institutional Animal Care and Use Committee of Osaka City University and were performed in accordance with the National Institutes of Health Guide for the Care and Use of Laboratory Animals.

\section{Anatomical tracing}

AAVs for anatomical tracing were produced by cotransfecting plasmids into 293T cells (RCB2202, Riken BRC), purified with heparin columns (HiTrap, GE Healthcare), and titered via quantitative polymerase chain reaction, as described previously (6). Plasmids used for AAV production were as follows: pAAV-EF1 $\alpha$-EGFP (6), pAAV-EF1 $\alpha$-DIO-EYFP (no. 20296, Addgene), pAAV-pgk-Cre (no. 24593, Addgene), pXR1 (National Gene Vector Biorepository),
pAAV2/6 (PL-T-PV0004, Penn Vector Core), pAAV-RC (AAV Helper-Free System, Stratagene), and pHelper (AAV HelperFree System).

Stereotaxic injections were performed on male Long-Evans rats ( $n=2,13$, and 12 rats for anterograde tracing, retrograde tracing, and projection-specific labeling, respectively; 262 to $382 \mathrm{~g} ; 7.9$ to 10 weeks old on the day of surgery; SLC, Japan) under $2 \%$ isoflurane anesthesia. For anterograde tracing, $400 \mathrm{nl}$ of AAV1/2-EF1 $\alpha$-EGFP $\left[2.9 \times 10^{13}\right.$ genome copies $\left.(\mathrm{GC}) / \mathrm{ml}\right]$ was injected into the left dorsal SUB [anterior-posterior from bregma (AP): $-6.1 \mathrm{~mm}$, mediolateral from the midline $(\mathrm{ML}): 3.0 \mathrm{~mm}$, dorsoventral from the cortical surface (DV): $2.8 \mathrm{~mm}$ ]. For retrograde tracing, either 400 or $1200 \mathrm{nl}$ per site of $0.5 \%(\mathrm{w} / \mathrm{v})$ CTB488 (C34775, Thermo Fisher Scientific) was injected into one of the following brain areas: bilateral NAC $(n=4$ rats; AP: $+2.4 \mathrm{~mm}, \mathrm{ML}: \pm 1.8 \mathrm{~mm}, \mathrm{DV}: 6.4 \mathrm{~mm})$, bilateral AV ( $n=2$ rats; AP: -2.0 or $-1.7 \mathrm{~mm}, \mathrm{ML}: \pm 1.6 \mathrm{~mm}$, and DV: $5.2 \mathrm{~mm}$ ), ITN ( $n=2$ rats; AP: $-2.0 \mathrm{~mm}$, ML: $1.0 \mathrm{~mm}$, DV: $6.6 \mathrm{~mm}$, inserted from the right hemisphere at an angle of $10^{\circ}$ in the coronal plane with the tip pointing toward the medial direction), bilateral RSC ( $n=2$ rats; AP: $-3.8 \mathrm{~mm}, \mathrm{ML}: \pm 0.4 \mathrm{~mm}, \mathrm{DV}: 1.6 \mathrm{~mm})$, and $\mathrm{MMB}(n=3$ rats; AP: $-4.7,-4.2$, or $-3.2 \mathrm{~mm}$; ML: $1.5 \mathrm{~mm}$; DV: $8.9,9.1$, or $9.3 \mathrm{~mm}$, at a $10^{\circ}$ angle as described above). For projection-specific labeling, $1000 \mathrm{nl}$ per site of AAV1/2-EF1 $\alpha$-DIO-EYFP $\left(9.2 \times 10^{11} \mathrm{GC} / \mathrm{ml}\right)$ was injected into the bilateral dorsal SUB (AP: $-6.1 \mathrm{~mm}, \mathrm{ML}: \pm 3.0 \mathrm{~mm}$, DV: $2.8 \mathrm{~mm})$, and $400 \mathrm{nl}$ per site of AAV6-pgk-Cre $\left(2.4 \times 10^{12} \mathrm{GC} / \mathrm{ml}\right)$ was injected into one of the following brain areas: bilateral NAC ( $n=3$ rats; AP: $+2.4 \mathrm{~mm}, \mathrm{ML}: \pm 1.8 \mathrm{~mm}, \mathrm{DV}: 6.4 \mathrm{~mm})$, bilateral AV ( $n=2$ rats; AP: $-2.0 \mathrm{~mm}, \mathrm{ML}: \pm 1.6 \mathrm{~mm}, \mathrm{DV}: 5.2 \mathrm{~mm}), \mathrm{ITN}(n=2$ rats; AP: $-2.0 \mathrm{~mm}$, ML: $1.0 \mathrm{~mm}, \mathrm{DV}: 6.4 \mathrm{~mm}$, at a $10^{\circ}$ angle as described above), bilateral RSC ( $n=3$ rats; AP: $-3.8 \mathrm{~mm}, \mathrm{ML}: \pm 0.4 \mathrm{~mm}$, DV: $2.0 \mathrm{~mm}$ ), and MMB ( $n=2$ rats; AP: $-4.7 \mathrm{~mm}$, ML: $1.5 \mathrm{~mm}, \mathrm{DV}$ : $8.9 \mathrm{~mm}$, at a $10^{\circ}$ angle as described above).

Immunohistochemistry was performed as described in the "Histology" section. Cells positive for CTB488, NOS, or PCP4 were counted manually using Fiji software at four or five AP levels of the SUB (350 to $2150 \mu \mathrm{m}$ posterior to the posterior commissure). In individual images, $10 \times 2$ and $10 \times 5$ grids were placed on the deep cell layer, rich in PCP4-positive cells (35), and the superficial cell layer, scarce in PCP4-positive cells, of the SUB, respectively. The density of CTB488-positive cells in each grid was obtained as the number of CTB488-positive cells in the grid divided by the grid area. Dendritic spines of EYFP-labeled dendrites were semiautomatically detected and measured from confocal image stacks (voxel size, $0.1 \mu \mathrm{m} \times 0.1 \mu \mathrm{m} \times 0.5 \mu \mathrm{m})$ using the NeuronStudio software, as described previously (78). Spines were classified into three groups according to their shape: mushroom, thin, and stubby. Spine density was calculated as the number of spines divided by the dendrite length.

\section{Materials for extracellular recordings}

We used three types of 256-channel silicon probes (NeuroNexus). All types had eight shanks, with each shank containing linearly aligned 32 recording sites ( 160 to $177 \mu \mathrm{m}^{2}$ per site, $0.61 \pm 0.23$ megohm at $1 \mathrm{kHz}$ ) but differing in their horizontal shank separation and vertical site spacing. Buzsaki256 probes had $300-\mu \mathrm{m}$ shank separation and $50-\mu \mathrm{m}$ vertical site spacing. A8x32-5mm-35-300-160 probes had $300-\mu \mathrm{m}$ shank separation and $35-\mu \mathrm{m}$ site spacing. A8x32-Edge$5 \mathrm{~mm}-25-200-177$ probes had $200-\mu \mathrm{m}$ shank separation and $25-\mu \mathrm{m}$ site spacing. The silicon probes were mounted on a $3 \mathrm{D}$-printed 
microdrive with a movable screw (R0090B500, J.I. Morris), with which the silicon probe was gradually lowered to the SUB/CA1 area after implantation. For 8 of the 11 implantations, all recording sites were coated with poly(3,4-ethylenedioxythiophene) conducting polymer (79) with a $1-\mu \mathrm{A}$ direct current for $3 \mathrm{~s}$ (nanoZ, White Matter) to lower the impedance $(0.44 \pm 0.20$ megohm at $1 \mathrm{kHz}$ after coating).

Laser diodes (450-nm light; PL450B, Osram) were coupled with a short optic fiber of $105-\mu \mathrm{m}$ (FG105LCA, Thorlabs) or $200-\mu \mathrm{m}$ (FP200URT, Thorlabs) core diameter (3.0 to $22.0 \mathrm{~mm}$ length depending on the target brain area). Light emission was controlled by a laser diode driver (LD202C, Thorlabs) and was measured before surgery from the tip of the optic fibers to reach 24 to $31 \mathrm{~mW}$ (with FG105LCA) and 42 to $88 \mathrm{~mW}$ (with FP200URT) with $100 \%$ laser output power.

\section{Surgery for recordings}

Eleven male Long-Evans rats (293 to 490 g; 8.9 to 15.3 weeks old on the day of surgery; SLC) were used. Under 1.6 to $2.0 \%$ isoflurane anesthesia, eight rats were stereotaxically implanted with four laser diode-coupled optic fibers targeting the left NAC (AP: $+2.4 \mathrm{~mm}$, ML: $1.8 \mathrm{~mm}$, DV: $6.3 \mathrm{~mm}$ ), left AV (AP: $-2.0 \mathrm{~mm}$, ML: $1.6 \mathrm{~mm}, \mathrm{DV}$ : 4.6 to $4.8 \mathrm{~mm}$ ), left RSC (AP: $-3.8 \mathrm{~mm}$, ML: $0.4 \mathrm{~mm}, \mathrm{DV}: 1.5 \mathrm{~mm}$ ), and MMB (AP: $-4.7 \mathrm{~mm}$, ML: $1.5 \mathrm{~mm}$, DV: $8.7 \mathrm{~mm}$, inserted from the right hemisphere at an angle of 10 degrees in the coronal plane with the tip pointing toward the medial direction) and were then injected with $800 \mathrm{nl}$ per site of AAV1-hSyn-hChR2(H134R)-EYFP $\left(2.3 \times 10^{13} \mathrm{GC} / \mathrm{ml}\right.$; Penn Vector Core; diluted 1:1 to 1:5 before injection) using a pulled glass pipet (G-1, Narishige) into two sites in the left dorsal SUB (AP: $-5.7 \mathrm{~mm}, \mathrm{ML}: 2.2$ to $2.5 \mathrm{~mm}, \mathrm{DV}: 2.9$ to $3.0 \mathrm{~mm}$ and AP: $-6.1 \mathrm{~mm}, \mathrm{ML}: 3.2$ to $3.5 \mathrm{~mm}, \mathrm{DV}: 2.9$ to $3.0 \mathrm{~mm}$ ). Rats were lastly implanted with a silicon probe targeting above the left dorsal SUB and distal CA1 area (center of the eight shanks at AP: -5.9 to $-6.1 \mathrm{~mm}, \mathrm{ML}: 2.7$ to $3.3 \mathrm{~mm}$, DV: $2.4 \mathrm{~mm}$, with shanks parallel to the coronal plane). Two stainless steel screws (B000FN0J58, Antrin Miniature Specialties) inserted above the cerebellum served as indifferent and ground electrodes. A faraday cage connected to the ground electrode was placed around the implants. One rat was subjected to the same surgery, but the optic fiber implantation to the MMB was omitted for a technical reason. Two rats were implanted only with a silicon probe above the dorsal SUB and distal CA1 area (center of shanks at AP: $-5.9 \mathrm{~mm}, \mathrm{ML}: 2.8$ to $3.3 \mathrm{~mm}, \mathrm{DV}: 2.4 \mathrm{~mm}$ ). All rats were housed individually after surgery.

\section{Data collection}

Electrophysiological data from behaving rats were acquired using a 256-channel, multiplexed recording system (KJE-1001, Amplipex) during behavioral tasks and sleep. Neurophysiological signals were amplified on a pre-amplifier module (HS-10, Amplipex) and acquired continuously at $20 \mathrm{kHz}$ with 16 -bit resolution. The silicon probe was lowered daily toward the SUB/CA1 area until large-amplitude units appeared approximately at the center of vertically aligned recording sites at a depth of 2.7 to $3.8 \mathrm{~mm}$ from the cortical surface. Characteristic features (power, phase, and polarity) of theta oscillations and SPW-Rs were used as additional guides to determine the approximate locations of the recording sites relative to the SUB/ CA1 cell layer $(17,19)$. The animal's position and head direction were tracked by monitoring two small light-emitting diodes (LEDs; green and red, 5-cm separation) mounted above the head-stage using an overhead camera (c930e, Logicool) at $\sim 30-\mathrm{Hz}$ sampling rate.
Single camera pixels corresponded to $0.41 \mathrm{~cm}$ for linear track and $0.52 \mathrm{~cm}$ for open-field, T-maze, zigzag maze, and rest sessions. LED positions were extracted and resampled to $39.0625 \mathrm{~Hz}$ for further analysis.

After the recording, to identify the location of recording sites, small electric lesions were made by passing anodal DC current $(3 \mu \mathrm{A}$ for $10 \mathrm{~s}$; A365, World Precision Instruments) through the most dorsal and ventral recording sites of each shank under anesthesia. Immunohistochemistry was performed as described in the "Histology" section. The tracks of silicon probe shanks and optic fibers were reconstructed from the images of serial sections.

The acquired local field potential (LFP) signals were downsampled to $1250 \mathrm{~Hz}$ for further analysis. Positive polarity is plotted upward throughout the study. Spike sorting was first performed automatically using the Kilosort software (https://github.com/cortex-lab/ KiloSort and https://github.com/MouseLand/Kilosort2), and then, clusters were adjusted manually using the phy gui (https://github. com/cortex-lab/phy), according to the developers' instructions. We measured cluster quality via the isolation distance and interspike interval (ISI) index, defined as the number of ISIs less than $2 \mathrm{~ms}$ divided by the number of ISIs between 2 and $10 \mathrm{~ms}$ multiplied by 4 $(6,32)$. Units satisfying all the following criteria were included for further analysis: isolation distance $>20$, ISI index $<0.2$, trough-topeak amplitude $>50 \mu \mathrm{V}$, and overall mean firing rate $>0.1 \mathrm{~Hz}$. Although we set these stringent criteria for unit quality, we cannot exclude that some units recorded in different sessions could have been identical, since spikes from sessions recorded on different days were clustered separately (table S1). We confirmed that even when single sessions per animal were used for analysis to remove this potential double counting, the statistical significance of pathwayspecific information routing (Figs. $4 \mathrm{~J}$ and $5 \mathrm{~K}$ ) was maintained.

\section{Behavioral procedures}

Rats were trained to perform four types of water-rewarded spatial tasks-namely, open-field, linear track, alternating T-maze, and zigzag maze tasks-daily for 7 to 9 days before and 4 to 8 days after surgery. During training, the experimenter gave water drops randomly in the arena (for the open-field task) or at the reward ports (for the other tasks, see below) to motivate animal movement. In the alternating T-maze task, only correct trials were rewarded. Then, 13 to 22 days after surgery ( 6 to 13 days for two rats not injected with $\mathrm{AAV}$ ), the recording sessions were carried out for two to three consecutive days, with the four behavioral tasks performed each day for $20 \mathrm{~min}$ each, and intertask rest sessions performed for 40 to $80 \mathrm{~min}$ each. Rest sessions were also carried out before the first behavioral task and after the final task. On the recording days, optical stimulation sessions to identify axonal projections were performed once (after all recording sessions of the day; one of the nine rats) or thrice (before, in the middle of, and after the recording sessions of the day; eight of the nine rats) while rats were resting in a small enclosure. During the periods of the behavioral experiments, rats were waterdeprived in a way to maintain $\sim 90 \%$ of their free-feeding body weight. All behavioral experiments were performed during the light period of the 12-hour light/dark cycle.

The open-field task was performed using a square black arena (118 cm by $118 \mathrm{~cm}, 40 \mathrm{~cm}$ deep, with an A4-sized white cue card on one of the walls), in which rats freely foraged for randomly dispersed drops of water. The linear track task was performed on an elevated black linear track (234-cm long, 6.5-cm wide, 54-cm high) on which 
rats were required to run back and forth to receive a $30-\mu$ l water drop supplied alternately at the edges of the track.

The alternating T-maze task was performed in a square black arena $(118 \mathrm{~cm}$ by $118 \mathrm{~cm}, 40-\mathrm{cm}$ deep) consisting of a start box (30 $\mathrm{cm}$ by $10 \mathrm{~cm}$ ), central runway (stem, $98-\mathrm{cm}$ long, $10-\mathrm{cm}$ wide), and left/right arms (10-cm wide). Rats were enclosed by doors in the start box for $\sim 8 \mathrm{~s}$ before allowed to run through the stem and arm. Rats were subjected to trials continuously and had to choose the other arm from that chosen in the previous trial to be rewarded with a $30-\mu l$ water drop at the end of the arm.

The zigzag maze task was performed in a square black arena (118 $\mathrm{cm}$ by $118 \mathrm{~cm}, 40-\mathrm{cm}$ deep), in which seven additional partitions (101-cm long, 30-cm high) were placed to form eight runways (118-cm long, 14-cm wide) connected with hairpin curves. Rats were rewarded with an $80-\mu$ l water drop alternately placed at the edges of the entire runway. During rest sessions, rats were placed in a small black enclosure ( $18 \mathrm{~cm}$ by $18 \mathrm{~cm}, 40-\mathrm{cm}$ deep) not containing a water reward; optical stimulation to identify axonal projections was also performed in this enclosure.

\section{Optogenetic identification of projection targets}

To identify the projection targets of recorded cells with antidromic spikes (31), we sequentially irradiated blue light pulses to the projection targets of the SUB while recording from the SUB and CA1. A single stimulation train consisted of 200 light pulses (10 pulses at $5 \mathrm{~Hz}$ repeated for 20 times with $\sim 1$-s intervals) and was repeated for combinations of 1 - or 5 -ms pulse durations with $12.5,25,50,75$, or $100 \%$ laser output power. Following these stimulation trains, closedloop stimulation was performed to efficiently detect spike collisions. For this, spikes were detected online by high-pass filtering the extracellular signals at $300 \mathrm{~Hz}$ and by thresholding at $3 \times$ root mean square, using a multi I/O processor (RX8, Tucker-Davis Technologies). Triggered by the detected spikes, a single light pulse (1-ms duration, $100 \%$ laser output power) was delivered to the target region with 1.8 -ms delay. To avoid burst stimulation, the minimum interstimulation interval was set to $200 \mathrm{~ms}$.

We identified projection neurons offline as follows. The peristimulus time histogram (0.5-ms bins) of individual cells was constructed for each stimulation train. Spikes in the first peak bin after stimulation onset ( $\geq 10$ spikes and $>$ mean +3 SD of the prestimulus baseline period) and in its contiguous bins (>mean $+1 \mathrm{SD}$ of the baseline period) were regarded as optically evoked spikes. Stimulation trains that gave low waveform correlation between the evoked and spontaneous spikes $(r<0.9)$ were excluded from further analysis. Fidelity for each stimulation train was calculated as the number of evoked spikes divided by that of stimulation trials (i.e., 200). Jitter was defined as the SD of time from stimulation onset to the evoked spikes. Latency was defined as the mean time from stimulation onset to the evoked spikes. In the stimulation train with the highest fidelity, the units satisfying all following criteria were defined as the neurons projecting to the stimulated area: fidelity $>20 \%$, jitter $<0.5 \mathrm{~ms}$, and latency $<25 \mathrm{~ms}$. These criteria were determined on the basis of the units that passed the spike collision test (see below).

Spike collision test was performed as follows. For a given evoked spike latency $t \mathrm{~ms}$, optical stimulation trials were divided into two types: collision trials that had one or more spontaneous spikes between $-t+1 \mathrm{~ms}$ and $t-1 \mathrm{~ms}$ (i.e., shortly before the expected evoked spike latency $t$ ) and the rest of the trials (noncollision trials). If the fidelity of optical spike generation in the collision trials was significantly less than that in noncollision trials $\left(P<0.05, \chi^{2}\right.$ test), the unit was regarded to pass the collision test. We used units that passed the spike collision test to define the criteria to identify projection target areas, so that $80 \%$ of the test-passed units were included in the criteria described above (fidelity $>20 \%$, jitter $<0.5 \mathrm{~ms}$, latency $<25 \mathrm{~ms}$ ) (fig. S3).

\section{Histology}

At specific days after the surgery for anatomical tracing (anterograde tracing: 15 days, retrograde tracing: 7 days, projection-specific labeling: 20 to 21 days) or soon after the electric lesions for localizing silicon probes, rats were transcardially perfused with $0.9 \%$ saline, followed by $4 \%$ paraformaldehyde in $0.1 \mathrm{M}$ phosphate buffer. The implanted silicon probe was pulled out before the brain was removed from the skull. Brains were stored in the same fixative overnight at $4^{\circ} \mathrm{C}$ and then sectioned using a vibratome (VT1200S, Leica) at a $50-\mu \mathrm{m}$ thickness parallel to the coronal plane. Sections were incubated sequentially with $5 \%$ bovine serum albumin (BSA) $/ 0.3 \%$ Triton $\mathrm{X}-100$ in phosphate-buffered saline (PBS) for $30 \mathrm{~min}$ at room temperature, primary antibodies in $5 \% \mathrm{BSA} / \mathrm{PBS}$ overnight at $4^{\circ} \mathrm{C}$, and the corresponding secondary antibodies conjugated with Alexa Fluor dyes in 5\% BSA/PBS for either 2 hours at room temperature or overnight at $4^{\circ} \mathrm{C}$. Some sections were counterstained with DAPI (4',6-diamidino-2-phenylindole; $0.5 \mu \mathrm{g} / \mathrm{ml}$; D1306, Thermo Fisher Scientific) and/or NeuroTrace Red fluorescent Nissl (1:200; N21482, Thermo Fisher Scientific). Between the incubation procedures, sections were washed with PBS. The primary antibodies used were as follows: chicken anti-GFP (green fluorescent protein) (1:2000; ab13970, Abcam), mouse anti-Cre recombinase (1:2000; MAB3120, Millipore), mouse anti-NeuN (1:2000; MAB377, Millipore), rabbit anti-PCP4 (1:200; HPA005792, Sigma-Aldrich), and sheep anti-NOS (1:10,000; gift from T. Fukuda, originally from P. C. Emson) (35). The following secondary antibodies were used at 1:800 dilution: goat anti-chicken immunoglobulin Y (IgY) conjugated with Alexa Fluor 488 (A-11039, Thermo Fisher Scientific), goat anti-mouse IgG with Alexa Fluor 594 (A-11032, Thermo Fisher Scientific), donkey antimouse IgG with Alexa Fluor 405 (ab175659, Abcam), donkey antirabbit IgG with Alexa Fluor 594 (A-21207, Thermo Fisher Scientific), and donkey anti-sheep IgG with Alexa Fluor 647 (A-21448, Invitrogen). Stained sections were mounted on coverslips with antifade mountant (P36961, Thermo Fisher Scientific). Tiled fluorescent images were taken using a confocal microscope (LSM700, Zeiss) equipped with $10 \times$ [numerical aperture $(\mathrm{NA})=0.45$, for anterograde tracing and for localizing silicon probe and optic fibers], $20 \times(\mathrm{NA}=0.8$, for retrograde tracing), and $63 \times(\mathrm{NA}=1.2$, for dendritic spines $)$ objectives.

\section{Cell classification}

We recorded a total of 791 well-isolated, large-amplitude units. Of these, 353 and 339 units were histologically identified to be localized in the CA1 area and SUB, respectively. Putative CA1 principal cells were defined as units that had $>0.4-\mathrm{ms}$ trough-to-peak spike width and $<10-\mathrm{Hz}$ overall mean firing rate. Putative SUB principal cells were defined as units that had $>0.4-\mathrm{ms}$ trough-to-peak spike width. The threshold of the mean firing rate was omitted when classifying SUB principal cells because a proportion of these cells shows high firing rates (fig. S3) (25). Accordingly, 315 and 319 units were identified as CA1 principal cells and SUB principal cells, respectively.

We verified the criteria of principal cell classification of CA1 and SUB neurons by detecting putative monosynaptic interactions (80). 
Cross-correlograms (CCGs) of spike timing were constructed for all pairs of simultaneously recorded cells (0.1-ms bins, Gaussian smoothing with $0.5-\mathrm{ms} \sigma$ ). For each pair, 199 surrogate CCGs were also constructed from data with random jittering of spike timing by -5 to $5 \mathrm{~ms}$ in one of the paired cells. The $99 \%$ global band significance level was calculated as described previously (80). CCGs with a peak or trough crossing the $99 \%$ significance level between 0 and $5 \mathrm{~ms}$ were taken as the candidate pairs of monosynaptic excitation or inhibition, respectively. Of these, dull peaks and troughs unlikely to be due to monosynaptic spike transmission and suppression were excluded by visual inspection. Nearly all CCG-based putative excitatory cells (CA1: 44 of 45 neurons, SUB: 40 of 40 neurons) were confirmed to meet the criteria of principal cells described above, and all CCG-based putative inhibitory cells (CA1: 6 of 6 neurons, SUB: 5 of 5 neurons) had $<0.4$-ms spike width (fig. S3, A to C). Hereafter, we analyzed only the CA1 and SUB principal cells.

\section{Place representation on a linear track}

We examined the spatial firing patterns on a linear track by constructing $1 \mathrm{D}$ rate maps for individual cells. A rate map consisted of firing rates at position bins $(2-\mathrm{cm}$ long, excluding the edges of the track), calculated by dividing the number of spikes in each position bin by the duration spent in that bin, after having individually smoothed both the numerator and denominator with a Gaussian filter $(\sigma=2 \mathrm{~cm})$. For each cell, rate maps were constructed separately for eastbound and westbound trials, and the rate map with the higher peak firing rate (i.e., the rate map of the cell's preferred direction) was used for further analysis. Cells with peak firing rates less than $1 \mathrm{~Hz}$ in the preferred direction were excluded from the analysis. The mean rate was defined as the mean firing rate during trials in the preferred direction. Spatial information per spike ( $I_{\text {spike, }}$ bits/spike) and spatial information per second $\left(I_{\mathrm{sec}}\right.$, bits/s) were calculated by

$$
\begin{gathered}
I_{\text {spike }}=\sum_{i} p_{i} \frac{\lambda_{i}}{\lambda} \log _{2}\left(\frac{\lambda_{i}}{\lambda}\right) \\
I_{\text {sec }}=\sum_{i} p_{i} \lambda_{i} \log _{2}\left(\frac{\lambda_{i}}{\lambda}\right)
\end{gathered}
$$

where $p_{i}$ is the proportion of time spent in the $i$ th position bin, $\lambda_{i}$ is the firing rate in the $i$ th position bin, and $\lambda$ is the mean firing rate during trials (38).

The chance level of $I_{\text {sec }}$ was obtained by a trial-wise shuffling procedure, by which the rate map of every trial was circularly shifted relative to the track position by a random interval, with the end of the trial wrapped to the beginning before obtaining the rate map averaged over trials. The shuffling was repeated 1000 times for each cell. A cell was defined as a place cell if its $I_{\text {sec }}$ value exceeded the 99th percentile of the $I_{\mathrm{sec}}$ value from the shuffled data obtained from all CA1 and SUB cells.

Mutual information (bits) of firing rates and places was estimated according to a previous study (39) by

$$
\text { Mutual information }=\sum_{i} \sum_{j} p_{i j} \log _{2}\left(\frac{p_{i j}}{p_{i} p_{j}}\right)
$$

where $p_{i}$ is the probability that the animal is in the $i$ th position bin (bin size, $2 \mathrm{~cm}$ ), $p_{j}$ is the probability that the instantaneous firing rate of a cell is in the $j$ th firing rate bin (four bins, see below), and $p_{i j}$ is the joint probability between the $i$ th position bin and $j$ th firing rate bin. The instantaneous firing rate of a cell was obtained by sorting the cell's spike timing into 25.6-ms bins, followed by Gaussian smoothing $(\sigma=128 \mathrm{~ms})$ of the binned firing rate. The instantaneous firing rates were sorted into four firing rate bins with threshold values at 25,50, and 75 percentiles of the nonzero instantaneous firing rate values.

\section{Place decoding on a linear track}

We performed memoryless Bayesian decoding of the rat's position to estimate the positional information conveyed by CA1 and SUB cell populations (40). The probability of the rat's position (pos) across $M$ total position bins in time window $\tau(250 \mathrm{~ms})$ containing neural spikes (spikes) was

$$
\operatorname{Pr}(\text { pos } \mid \text { spikes })=U / \sum_{i=1}^{M} U
$$

where

$$
U=\left(\prod_{j=1}^{N} f_{j}(\text { pos })^{n_{j}}\right) \exp \left(-\tau \sum_{j=1}^{N} f_{j}(\text { pos })\right)
$$

The $f_{j}$ (pos) is the rate map of the $j$ th unit, $n_{j}$ is the number of spikes of the $j$ th unit in the time window, and $N$ is the number of units used for decoding. Decoding performance was estimated using leave-one-out cross-validation as follows. From a given set of trials in the recording session, a trial was chosen as test data, and the rest of the trials were used as training data. The decoding result, $\operatorname{Pr}\left(\right.$ pos $\mid$ spikes), was obtained using rate maps $f_{j}($ pos $)$ constructed from the training data and spike train $n_{j}$ in the test data. The position with the highest $\operatorname{Pr}$ (pos|spikes) across the position bins was defined as the decoded position of the given time window. The decoding error of the test data was calculated as the mean Euclidean distance between the decoded and the observed positions. The decoding error was calculated either from all time bins, irrespective of the number of spikes in the bins, or from time bins containing one or more spikes, both of which gave essentially the same results (Fig. $3 \mathrm{H}$ ). This procedure was repeated to assign every trial as test data, and the decoding errors from all test data were averaged to obtain the decoding error of the session. The chance-level distribution of the decoding error was estimated by a shuffling procedure repeated 100 times: The decoded positions were randomly permuted along time windows, and the decoding error was calculated.

Dependency of the decoding performance on the number of used cells was measured by random cell subsampling. Of the total simultaneously recorded CA1 or SUB cells $\left(N_{\text {total }}\right)$, decoding was performed using a certain number of random cell subsets, and the decoding error was calculated. This procedure was repeated 100 times (or for all possible combinations of the cell group if the number of combinations was less than 100), and the obtained decoding errors were averaged over the repetition. By changing the number of units supplied for the decoding from 1 to $N_{\text {total }}$, we obtained the decoding error for each number of units.

To control the decoding performance for SUB high firing rate, the mean firing rate of SUB neurons was matched to that of CA1 neurons by randomly removing $\left(1-\lambda_{\mathrm{CA} 1} / \lambda_{\mathrm{SUB}}\right) \times 100 \%$ of spikes out of all spikes generated by SUB neurons, where $\lambda_{\text {CA1 }}$ and $\lambda_{\text {SUB }}$ were the mean firing rates averaged across CA1 and SUB neurons, 
respectively. We then performed the decoding analysis as described above using these subsampled SUB spikes.

To estimate the contribution of single units to the decoding performance, we performed a Jackknife procedure after random subsampling of the units. Of the total simultaneously recorded CA1 or SUB units, one unit was chosen as a test unit, and nine were randomly chosen from the remaining units. Recording sessions with less than 10 simultaneously recorded CA1 or SUB units were excluded from this analysis. Decoding was performed using the nine units with or without the test unit, and the decoding improvement of the test unit was calculated as the difference in the decoding error between the two decoding error values. The random choice of nine units was repeated 100 times from all possible combinations of nine units without replacement (or for all possible combinations of choices if the number of combinations was less than 100), and the decoding improvement of the test unit was averaged over the repetition. This procedure was further repeated to assign every recorded unit as a test unit once.

The robustness of the decoding performance against noise was estimated by randomly removing (up to $99 \%$ of the number of spikes of each unit) or adding spikes to every unit at a fixed frequency over the entire recording session before performing the decoding procedure with all simultaneously recorded CA1 or SUB cells. The removal/ addition procedure was repeated 100 times to obtain the decoding error, averaged over the repetition. Recording sessions with less than five simultaneously recorded units were excluded from this analysis. The entire decoding procedure was performed separately for eastbound and westbound runs, which were pooled later.

\section{Place representation in an open field}

We analyzed the spatial firing patterns in the open field similarly to those on the linear track. A rate map was constructed by $2 \times 2 \mathrm{~cm}$ position bins using a 2D Gaussian filter $(\sigma=4 \mathrm{~cm})$ for smoothing. Units with a mean firing rate less than $0.1 \mathrm{~Hz}$ in the open field were excluded from the analysis. Spatial information per spike $\left(I_{\text {spike, }}\right.$, bits/spike) and that per second ( $I_{\text {sec }}$, bits/s) was calculated exactly as those on the linear track. A session-wise shuffling procedure was performed, by which the spike train of the whole open-field session was circularly time-shifted relative to the rat's position by a random interval between $30 \mathrm{~s}$ and the length of the session minus $30 \mathrm{~s}$, with the end of the trial wrapped to the beginning.

We performed memoryless Bayesian decoding $(\tau=1 \mathrm{~s})$ as in the case of the linear track. Decoding performance was estimated using fivefold cross-validation as follows. The four-fifth periods of the recording session (e.g., 0 to $960 \mathrm{~s}$ of the 1200-s session) were chosen as the training data, and the remaining periods (e.g., 960 to $1200 \mathrm{~s}$ ) were assigned as the test data. The probability of the rat's position across position bins, $\operatorname{Pr}$ (pos|spikes), was calculated from rate maps $f_{j}$ (pos) constructed from the training data and spike train $n_{j}$ in the test data, as described above. This procedure was repeated five times to decode from all periods of the recording session, and the decoding errors from the five periods were averaged to obtain the decoding error of the session. The chance-level distribution of the decoding error was estimated by a shuffling procedure (100 repetitions), by which the decoded positions were randomly permuted along time bins, and the decoding error was calculated from the shuffled decoded positions and the observed positions. To control the decoding performance for SUB high firing rate, spikes were randomly removed from SUB neurons as described above, before performing the decoding analysis. Dependency of the decoding performance on the number of used cells and the robustness of the decoding performance against noise were also estimated as described for the linear track.

\section{Speed representation in an open field}

Speed representation in the open field was analyzed as described previously $(42,43)$. Neuronal spikes were sorted into 25.6 -ms time bins. The instantaneous firing rate was obtained by dividing the numbers of spikes for each cell by the bin size and smoothed with a Gaussian filter $(\sigma=256 \mathrm{~ms})$. Units with mean firing rate less than $0.1 \mathrm{~Hz}$ in the open field were excluded from the analysis. Each rat's positions were smoothed with a Gaussian filter $(\sigma=256 \mathrm{~ms})$. Instantaneous running speed was calculated by dividing the distance of the smoothed position between adjacent bins by the bin size $(25.6 \mathrm{~ms})$. Changing the SD of Gaussian filters to 128 or $512 \mathrm{~ms}$ for both firing rate and position gave similar results. Periods slower than $2 \mathrm{~cm} / \mathrm{s}$ and faster than $50 \mathrm{~cm} / \mathrm{s}$ were removed from the analysis. Speed scores were defined for each cell as the Pearson product-moment correlation coefficients between the cell's instantaneous firing rate and the rat's instantaneous running speed. We calculated speed information as follows (42). First, for each cell, the speed tuning curve of the firing rate against speed was constructed using bins of $4 \mathrm{~cm} / \mathrm{s}$, from 2 to $50 \mathrm{~cm} / \mathrm{s}$. Then, speed information per spike ( $I_{\text {spike, }}$, bits/spike) and speed information per second $\left(I_{\mathrm{sec}}, \mathrm{bits} / \mathrm{s}\right)$ were obtained by Eqs. 1 and 2, respectively, where $p_{i}$ is the proportion of time spent in the $i$ th speed bin, $\lambda_{i}$ is the firing rate in the $i$ th speed bin, and $\lambda$ is the mean firing rate in the open field.

Chance-level statistics were calculated by a shuffling procedure (100 repetition), by which the spike train was circularly time-shifted relative to the rat's position by a random interval between $30 \mathrm{~s}$ and the length of the session minus $30 \mathrm{~s}$, with the end of the trial wrapped to the beginning. A cell was defined as a positive speed (p-speed) cell or negative speed ( $n$-speed) cell if its speed score exceeded the 99th percentile or was lower than the 1st percentile, respectively, of the distribution of speed scores from the shuffled data from all CA1 and SUB principal cells. We used bootstrap analysis to determine whether a SUB projection neuron group contained a significantly higher proportion of p-speed cells (31).

\section{Decoding of running speed}

Decoding of running speed was performed using fivefold crossvalidation similar to a previous study (43). Of the 1200-s recording session in the open field, one-fifth of the period (e.g., 0 to $240 \mathrm{~s}$ ) was assigned as test data, and the remaining four-fifths (e.g., 240 to $1200 \mathrm{~s}$ ) were used as training data. A linear relationship between the firing rate and running speed averaged over 1-s bins was expressed as

$$
S_{\mathrm{tr}}=R_{\mathrm{tr}} f
$$

where $S_{\text {tr }}$ is a column vector with the speed bins of the training data, $R_{\text {tr }}$ is a matrix containing the corresponding firing rate bins for each neuron as columns and an additional column of 1 s to account for $y$ intercepts, and $f$ is a linear filter used as a column vector with a length equal to the number of cells plus 1 . The linear filter $f$ was obtained by

$$
f=R_{\mathrm{tr}}{ }^{+} S_{\mathrm{tr}}
$$

where $R_{\mathrm{tr}}{ }^{+}$is the Moore-Penrose pseudoinverse of $R_{\mathrm{tr}}$. Once $f$ was obtained, the decoded speed $S_{\text {dec }}$ was calculated by 


$$
S_{\text {dec }}=R_{\text {test }} f
$$

where $R_{\text {test }}$ is the firing rate matrix of the test data. Decoding accuracy was defined as the Pearson correlation coefficient between $S_{\mathrm{dec}}$ and the observed speed $S_{\text {test }}$. The chance level of the decoding accuracy was estimated by a shuffling procedure repeated 100 times, by which $S_{\text {dec }}$ was time-shifted by a random interval between 30 and $210 \mathrm{~s}$ relative to $S_{\text {test }}$. The decoding procedure was repeated five times to decode all periods of the recording session, and the obtained decoding accuracy was averaged over the five periods. Dependency of the decoding performance on the number of used cells was measured by random subsampling of the cells, as described above. The single-unit decoding accuracy refers to the accuracy obtained from the decoding using single units. To control the decoding performance for SUB high firing rate, spikes were randomly removed from SUB neurons as described above, before performing the decoding analysis.

Robustness of the decoding performance against noise was estimated by randomly removing (up to $99 \%$ of the number of spikes of the unit) or adding spikes to every unit at a fixed frequency over the entire recording session before performing the decoding procedure with all the simultaneously recorded CA1 or SUB units. The removal/ addition procedure was repeated 100 times to obtain the decoding accuracy, averaged over the repetition. The normalized accuracy was obtained as the decoding accuracy values divided by the corresponding decoding accuracy without the spike removal/addition. Recording sessions containing less than five units were excluded from this analysis.

\section{Trajectory-dependent firing in an alternating T-maze}

Trajectory-dependent firing in the start box of the T-maze was analyzed. A trial comprised a wait period of $\sim 8 \mathrm{~s}$ in the start box, running through the stem and left or right arm, reward acquisition at the end of the arm, and return to the start box. To estimate the strength of trajectory-dependent firing in the start box, we obtained the following parameters for each neuron using firing rates in the start box: trajectory information per spike ( $I_{\text {spike }}$, bits/spike) and trajectory information per second ( $I_{\mathrm{sec}}$, bits/s), calculated by Eqs. 1 and 2, respectively, where $i$ is the identifier of left or right choices, $p_{i}$ is the proportion of choice $i, \lambda_{i}$ is the mean firing rate in the start box for the subsequent choice $i$, and $\lambda$ is the mean firing rate in the start box. Units with $\lambda_{i}<0.1 \mathrm{~Hz}$ for both left and right choices were excluded from the analysis. The rate change ratio was defined as $\left|\lambda_{L}-\lambda_{R}\right| /$ $\max \left(\lambda_{\mathrm{L}}, \lambda_{\mathrm{R}}\right)$, where $\lambda_{\mathrm{L}}$ and $\lambda_{\mathrm{R}}$ are the firing rates in the start box averaged over left- and right-arm trials, respectively. The auROC (ranging from 0 to 1 ) was calculated to estimate the goodness of fit of the binary classifier (i.e., left- or right-arm trials) from the mean firing rates in the start box using the "perfcurve" function in MATLAB. For auROC values less than $0.5,1-$ auROC was assigned as the new auROC value, as the experimenter had no prior knowledge on the type of trials (left or right) that neurons showed a higher firing rate. We defined trajectory-dependent cells as neurons whose firing rates in the start box were significantly different between leftand right-arm trials $(P<0.05$, Wilcoxon rank sum test). We used bootstrap analysis to determine whether a SUB projection neuron group contained a significantly higher proportion of trajectorydependent cells (31).

\section{Decoding of trajectory}

Trajectory decoding was performed using a support vector machine algorithm and leave-one-out cross-validation, according to a previous study (5). From a given set of trials in the recording session, one trial was assigned as test data, and the remaining trials were used as the training dataset. A binary classifier was constructed to predict the next trajectory (left or right) from the firing rates in the start box, using the "fitcsvm" function in MATLAB, in which the input arguments were matrix $F$ consisting of the firing rates of individual neurons (columns) in the training trials (rows) and vector $y$ consisting of the trajectory label $(-1,1)$ of the training trials. Using the firing rates in the test trial as an input to the constructed classifier, the trajectory in the test trial was predicted. This decoding procedure was repeated to assign every trial as test data once, and the decoding accuracy was defined as the proportion of correctly predicted trials. Dependency of the decoding performance on the number of used cells was measured by random subsampling of the cells, as described above. The chance level of the decoding accuracy was estimated by a shuffling procedure repeated 100 times, by which trajectory labels were randomly shuffled before constructing the classifier. To control the decoding performance for SUB high firing rate, spikes were randomly removed from SUB neurons as described above, before performing the decoding analysis.

The robustness of the decoding performance against noise was estimated by randomly removing (up to $99 \%$ of the number of spikes of the unit) or adding spikes to every unit at a fixed frequency over the entire recording session before performing the decoding procedure with all the simultaneously recorded CA1 or SUB units. The removal/addition procedure was repeated 100 times to obtain the decoding accuracy averaged over the repetition. The normalized accuracy was obtained as follows: (decoding accuracy - 0.5)/(corresponding decoding accuracy without the spike removal/addition -0.5$)$. $\mathrm{Re}$ cording sessions containing less than five units were excluded from this analysis.

\section{Head-direction representation in an open field}

We analyzed the head-direction tuning in the open field by constructing directional rate maps for individual cells. A directional rate map consisted of firing rates at $1^{\circ}$ directional bins smoothed by Gaussian filter $\left(\sigma=5^{\circ}\right)$. Units with a mean firing rate less than $0.1 \mathrm{~Hz}$ in the open field were excluded from the analyses. Directional information per spike $\left(I_{\text {spike, }}\right.$ bits/spike) and that per second $\left(I_{\mathrm{sec}}, \mathrm{bits} / \mathrm{s}\right)$ were calculated by Eqs. 1 and 2, respectively, where $p_{i}$ is the proportion of time spent in the $i$ th directional bin, $\lambda_{i}$ is the firing rate in the $i$ th directional bin, and $\lambda$ is the mean firing rate in the open field. The chance level of $I_{\text {sec }}$ was obtained by a session-wise shuffling procedure of spike timing against the rat's position. A cell was defined as a head-direction cell if its $I_{\text {sec }}$ value exceeded the 99th percentile of the $I_{\mathrm{sec}}$ value from the shuffled data obtained from all CA1 and SUB cells. Strength of directional tuning was measured with the mean vector length of head directions when spikes occurred. We performed memoryless Bayesian decoding of head direction $\left(\tau=250 \mathrm{~ms}, 1^{\circ}\right.$ directional bins) similarly with place decoding in an open field. Decoding performance was estimated using fivefold cross-validation. The decoding error was obtained as the mean of the absolute angular differences between the decoded and observed head direction.

\section{Behavioral states}

Throughout the recording sessions, each second of behavior was classified into four states: RUN, REST, REM sleep, or SWS. This classification was carried out by visual inspection of the power spectra of SUB LFPs, SUB raw LFP traces, and electromyogram (EMG)-related 
signals extracted as correlations of LFPs in distant channels after filtering at 300 to $600 \mathrm{~Hz}$ (81). RUN states were defined as the periods during behavioral tasks with prominent theta oscillations and EMGrelated signals. REST was defined as the awake, resting state detected during rest sessions without theta oscillations but with EMG-related signals. REM sleep was detected by the presence of robust theta oscillations and the absence of EMG-related signals during rest sessions. SWS was detected by the absence of both theta oscillations and EMG-related signals during rest sessions.

\section{Theta oscillations}

The power spectra density of LFP during RUN and REM periods was obtained using the Welch periodogram method (50\% overlapping Hamming windows with a length of $2 \mathrm{~s}$ ). Theta power was obtained as the mean power spectra density (in decibels) between 5 and $10 \mathrm{~Hz}$. A recording site with maximal theta power approximately at the center of the SUB cell layer was used as the reference site to determine phase deviation and phase locking. Instantaneous theta phase was derived from the Hilbert transform of the bandpass-filtered (5- to $10-\mathrm{Hz}$ ) LFP trace (troughs $=0^{\circ}$ and $360^{\circ}$ and peaks $=180^{\circ}$ throughout this study). Theta phase deviation was calculated as the mean circular distance of instantaneous theta phases between the reference recording site and the recording site of interest. Spike theta phase, i.e., the theta phase at which the spike occurred, was obtained for every spike. The preferred theta phase of each neuron was defined as the circular mean of the spike theta phases. PPC, a firing rate-insensitive measure of phase-locking strength, was calculated by

$$
\mathrm{PPC}=\frac{2}{N(N-1)} \sum_{i=1}^{N-1} \sum_{j=i+1}^{N}\left\{\cos \left(\theta_{i}\right) \cos \left(\theta_{j}\right)+\sin \left(\theta_{i}\right) \sin \left(\theta_{j}\right)\right\}
$$

where $N$ is the total spike number, and $\theta_{i}$ is the spike theta phase of the $i$ th spike (46).

\section{SPW-R-associated firing}

Spike timing along SPW-Rs was examined during SWS and REST periods. The ripple-band LFP signal was obtained as the bandpassfiltered LFP signal ( 140 to $230 \mathrm{~Hz}$ ) at the center of the SUB cell layer. Normalized ripple power was calculated as the $z$-scored moving average (window size, 11 samples) of squared ripple-band LFP signals. Periods with a normalized ripple power exceeding three were collected as candidate ripple events. Temporally close candidate events ( $<30-\mathrm{ms}$ interevent intervals) were merged into single events. The candidate events with low peak normalized ripple power $(<7)$, too short duration $(<15 \mathrm{~ms})$, or too long duration $(>300 \mathrm{~ms})$ were discarded, and the remaining events were defined as ripple events. Ripple timing was determined as the timing of the negative peak of the bandpass-filtered LFP signal (140 to $230 \mathrm{~Hz}$ ) in each event. Ripple power was defined as the peak value of the normalized ripple power in each ripple event. Ripple duration was defined as the duration of the normalized ripple power exceeding three. Ripple frequency was defined as the frequency with maximal wavelet power between 140 and $230 \mathrm{~Hz}$ at the ripple timing. A peri-event time histogram (5-ms bins) was constructed for each ripple event for each cell, averaged across all events, and $z$-scored. The peak height for each neuron was defined as the mean $z$-scored peri-event time histogram between -10 and $+10 \mathrm{~ms}$. All data analyses were performed by custom-written MATLAB codes.

\section{Statistical analysis}

Statistical analysis was performed using MATLAB (MathWorks) and SPSS Statistics (IBM). All statistical tests were two-sided. Error bars indicate means \pm SD unless otherwise noted.

\section{SUPPLEMENTARY MATERIALS}

Supplementary material for this article is available at http://advances.sciencemag.org/cgi/ content/full/7/11/eabf1913/DC1

View/request a protocol for this paper from Bio-protocol.

\section{REFERENCES AND NOTES}

1. J. L. Calton, R. W. Stackman, J. P. Goodridge, W. B. Archey, P. A. Dudchenko, J. S. Taube, Hippocampal place cell instability after lesions of the head direction cell network. J. Neurosci. 23, 9719-9731 (2003)

2. N. A. Russell, A. Horii, P. F. Smith, C. L. Darlington, D. K. Bilkey, Long-term effects of permanent vestibular lesions on hippocampal spatial firing. J. Neurosci. 23, 6490-6498 (2003).

3. V. H. Brun, S. Leutgeb, H. Q. Wu, R. Schwarcz, M. P. Witter, E. I. Moser, M. B. Moser, Impaired spatial representation in $\mathrm{CA} 1$ after lesion of direct input from entorhinal cortex. Neuron 57, 290-302 (2008).

4. T. Nakashiba, J. Z. Young, T. J. McHugh, D. L. Buhl, S. Tonegawa, Transgenic inhibition of synaptic transmission reveals role of CA3 output in hippocampal learning. Science $\mathbf{3 1 9}$, 1260-1264 (2008).

5. H. T. Ito, S. J. Zhang, M. P. Witter, E. I. Moser, M. B. Moser, A prefrontal-thalamohippocampal circuit for goal-directed spatial navigation. Nature 522, 50-55 (2015).

6. T. Kitanishi, S. Ujita, M. Fallahnezhad, N. Kitanishi, Y. Ikegaya, A. Tashiro, Novelty-induced phase-locked firing to slow gamma oscillations in the hippocampus: Requirement of synaptic plasticity. Neuron 86, 1265-1276 (2015).

7. H. Davoudi, D. J. Foster, Acute silencing of hippocampal CA3 reveals a dominant role in place field responses. Nat. Neurosci. 22, 337-342 (2019).

8. J. O'Keefe, J. Dostrovsky, The hippocampus as a spatial map. Preliminary evidence from unit activity in the freely-moving rat. Brain Res. 34, 171-175 (1971).

9. B. L. McNaughton, C. A. Barnes, J. O'Keefe, The contributions of position, direction, and velocity to single unit activity in the hippocampus of freely-moving rats. Exp. Brain Res. 52, 41-49 (1983).

10. E. R. Wood, P. A. Dudchenko, R. J. Robitsek, H. Eichenbaum, Hippocampal neurons encode information about different types of memory episodes occurring in the same location. Neuron 27, 623-633 (2000).

11. L. M. Frank, E. N. Brown, M. Wilson, Trajectory encoding in the hippocampus and entorhinal cortex. Neuron 27, 169-178 (2000).

12. J. A. Ainge, M. A. van der Meer, R. F. Langston, E. R. Wood, Exploring the role of contextdependent hippocampal activity in spatial alternation behavior. Hippocampus 17, 988-1002 (2007).

13. L. Acharya, Z. M. Aghajan, C. Vuong, J. J. Moore, M. R. Mehta, Causal influence of visual cues on hippocampal directional selectivity. Cell 164, 197-207 (2016).

14. E. Pastalkova, V. Itskov, A. Amarasingham, G. Buzsaki, Internally generated cell assembly sequences in the rat hippocampus. Science 321, 1322-1327 (2008).

15. C. J. MacDonald, K. Q. Lepage, U. T. Eden, H. Eichenbaum, Hippocampal "time cells" bridge the gap in memory for discontiguous events. Neuron 71, 737-749 (2011).

16. B. J. Kraus, R. J. Robinson II, J. A. White, H. Eichenbaum, M. E. Hasselmo, Hippocampal "time cells": Time versus path integration. Neuron 78, 1090-1101 (2013).

17. G. Buzsaki, Theta oscillations in the hippocampus. Neuron 33, 325-340 (2002).

18. G. Buzsaki, X. J. Wang, Mechanisms of gamma oscillations. Annu. Rev. Neurosci. 35, 203-225 (2012).

19. G. Buzsaki, Hippocampal sharp wave-ripple: A cognitive biomarker for episodic memory and planning. Hippocampus 25, 1073-1188 (2015).

20. N. Matsumoto, T. Kitanishi, K. Mizuseki, The subiculum: Unique hippocampal hub and more. Neurosci. Res. 143, 1-12 (2019).

21. E. J. Henriksen, L. L. Colgin, C. A. Barnes, M. P. Witter, M. B. Moser, E. I. Moser, Spatial representation along the proximodistal axis of CA1. Neuron 68, 127-137 (2010).

22. P. A. Naber, M. P. Witter, Subicular efferents are organized mostly as parallel projections: A double-labeling, retrograde-tracing study in the rat. J. Comp. Neurol. 393, 284-297 (1998).

23. M. S. Cembrowski, M. G. Phillips, S. F. DiLisio, B. C. Shields, J. Winnubst, J. Chandrashekar, E. Bas, N. Spruston, Dissociable structural and functional hippocampal outputs via distinct subiculum cell classes. Cell 173, 1280-1292.e18 (2018)

24. C. A. Barnes, B. L. McNaughton, S. J. Mizumori, B. W. Leonard, L. H. Lin, Comparison of spatial and temporal characteristics of neuronal activity in sequential stages of hippocampal processing. Prog. Brain Res. 83, 287-300 (1990).

25. P. E. Sharp, C. Green, Spatial correlates of firing patterns of single cells in the subiculum of the freely moving rat. J. Neurosci. 14, 2339-2356 (1994). 
26. S. M. Kim, S. Ganguli, L. M. Frank, Spatial information outflow from the hippocampal circuit: Distributed spatial coding and phase precession in the subiculum. J. Neurosci. 32, 11539-11558 (2012).

27. J. M. Olson, K. Tongprasearth, D. A. Nitz, Subiculum neurons map the current axis of travel. Nat. Neurosci. 20, 170-172 (2017).

28. C. Lever, S. Burton, A. Jeewajee, J. O'Keefe, N. Burgess, Boundary vector cells in the subiculum of the hippocampal formation. J. Neurosci. 29, 9771-9777 (2009).

29. J. L. Gauthier, D. W. Tank, A dedicated population for reward coding in the hippocampus. Neuron 99, 179-193.e7 (2018).

30. D. S. Roy, T. Kitamura, T. Okuyama, S. K. Ogawa, C. Sun, Y. Obata, A. Yoshiki, S. Tonegawa, Distinct neural circuits for the formation and retrieval of episodic memories. Cell 170, 1000-1012.e19 (2017).

31. S. Ciocchi, J. Passecker, H. Malagon-Vina, N. Mikus, T. Klausberger, Selective information routing by ventral hippocampal CA1 projection neurons. Science 348, 560-563 (2015).

32. K. Mizuseki, K. Diba, E. Pastalkova, G. Buzsaki, Hippocampal CA1 pyramidal cells form functionally distinct sublayers. Nat. Neurosci. 14, 1174-1181 (2011).

33. A. Berényi, Z. Somogyvári, A. J. Nagy, L. Roux, J. D. Long, S. Fujisawa, E. Stark, A. Leonardo, T. D. Harris, G. Buzsáki, Large-scale, high-density (up to 512 channels) recording of local circuits in behaving animals. J. Neurophysiol. 111, 1132-1149 (2014).

34. N. Ishizuka, Laminar organization of the pyramidal cell layer of the subiculum in the rat. J. Comp. Neurol. 435, 89-110 (2001).

35. Y. Ishihara, T. Fukuda, Immunohistochemical investigation of the internal structure of the mouse subiculum. Neuroscience 337, 242-266 (2016).

36. J. Winnubst, E. Bas, T. A. Ferreira, Z. Wu, M. N. Economo, P. Edson, B. J. Arthur, C. Bruns, K. Rokicki, D. Schauder, D. J. Olbris, S. D. Murphy, D. G. Ackerman, C. Arshadi, P. Baldwin, R. Blake, A. Elsayed, M. Hasan, D. Ramirez, B. D. Santos, M. Weldon, A. Zafar, J. T. Dudman, C. R. Gerfen, A. W. Hantman, W. Korff, S. M. Sternson, N. Spruston, K. Svoboda, J. Chandrashekar, Reconstruction of 1,000 projection neurons reveals new cell types and organization of long-range connectivity in the mouse brain. Cell 179, 268-281.e13 (2019).

37. L. Kinnavane, S. D. Vann, A. J. D. Nelson, S. M. O'Mara, J. P. Aggleton, Collateral projections innervate the mammillary bodies and retrosplenial cortex: A new category of hippocampal cells. eNeuro 5, ENEURO.0383-17.2018 (2018).

38. W. E. Skaggs, B. L. McNaughton, K. M. Gothard, E. J. Markus, An information-theoretic approach to deciphering the hippocampal code. Adv. Neural. Inf. Process. Syst. 5, 1030-1037 (1993).

39. B. C. Souza, R. Pavao, H. Belchior, A. B. L. Tort, On information metrics for spatial coding. Neuroscience 375, 62-73 (2018).

40. B. E. Pfeiffer, D. J. Foster, Hippocampal place-cell sequences depict future paths to remembered goals. Nature 497, 74-79 (2013).

41. A. A. Faisal, L. P. Selen, D. M. Wolpert, Noise in the nervous system. Nat. Rev. Neurosci. 9, 292-303 (2008).

42. M. Iwase, T. Kitanishi, K. Mizuseki, Cell type, sub-region, and layer-specific speed representation in the hippocampal-entorhinal circuit. Sci. Rep. 10, 1407 (2020).

43. E. Kropff, J. E. Carmichael, M. B. Moser, E. I. Moser, Speed cells in the medial entorhinal cortex. Nature 523, 419-424 (2015).

44. R. U. Muller, E. Bostock, J. S. Taube, J. L. Kubie, On the directional firing properties of hippocampal place cells. J. Neurosci. 14, 7235-7251 (1994).

45. A. Peyrache, M. M. Lacroix, P. C. Petersen, G. Buzsaki, Internally organized mechanisms of the head direction sense. Nat. Neurosci. 18, 569-575 (2015).

46. M. Vinck, M. van Wingerden, T. Womelsdorf, P. Fries, C. M. Pennartz, The pairwise phase consistency: A bias-free measure of rhythmic neuronal synchronization. Neuroimage $\mathbf{5 1}$ 112-122 (2010).

47. N. Nitzan, S. McKenzie, P. Beed, D. F. English, S. Oldani, J. J. Tukker, G. Buzsáki, D. Schmitz, Propagation of hippocampal ripples to the neocortex by way of a subiculum-retrosplenial pathway. Nat. Commun. 11, 1947 (2020).

48. K. D. Harris, H. Hirase, X. Leinekugel, D. A. Henze, G. Buzsaki, Temporal interaction between single spikes and complex spike bursts in hippocampal pyramidal cells. Neuron 32, 141-149 (2001).

49. J. Simonnet, M. Brecht, Burst firing and spatial coding in subicular principal cells. J. Neurosci. 39, 3651-3662 (2019).

50. K. D. Harris, J. Csicsvari, H. Hirase, G. Dragoi, G. Buzsaki, Organization of cell assemblies in the hippocampus. Nature 424, 552-556 (2003).

51. D. O. Hebb, The Organization of Behavior; A Neuropsychological Theory (Wiley, 1949), p. $x i x, 335$ pp.

52. S. Nirenberg, P. E. Latham, Decoding neuronal spike trains: How important are correlations? Proc. Natl. Acad. Sci. U.S.A. 100, 7348-7353 (2003).

53. S. Leutgeb, J. K. Leutgeb, A. Treves, M. B. Moser, E. I. Moser, Distinct ensemble codes in hippocampal areas CA3 and CA1. Science 305, 1295-1298 (2004).

54. K. Mizuseki, S. Royer, K. Diba, G. Buzsaki, Activity dynamics and behavioral correlates of CA3 and CA1 hippocampal pyramidal neurons. Hippocampus 22, 1659-1680 (2012).
55. D. GoodSmith, X. Chen, C. Wang, S. H. Kim, H. Song, A. Burgalossi, K. M. Christian, J. J. Knierim, Spatial representations of granule cells and mossy cells of the dentate gyrus. Neuron 93, 677-690.e5 (2017)

56. M. W. Jung, B. L. McNaughton, Spatial selectivity of unit activity in the hippocampal granular layer. Hippocampus 3, 165-182 (1993).

57. M. Diamantaki, M. Frey, P. Berens, P. Preston-Ferrer, A. Burgalossi, Sparse activity of identified dentate granule cells during spatial exploration. eLife 5, e20252 (2016).

58. Y. Senzai, G. Buzsaki, Physiological properties and behavioral correlates of hippocampal granule cells and mossy cells. Neuron 93, 691-704.e5 (2017).

59. S. D. Vann, J. P. Aggleton, The mammillary bodies: Two memory systems in one? Nat. Rev. Neurosci. 5, 35-44 (2004).

60. D. Mao, L. A. Molina, V. Bonin, B. L. McNaughton, Vision and locomotion combine to drive path integration sequences in mouse retrosplenial cortex. Curr. Biol. 30, 1680-1688.e4 (2020).

61. C. Chinzorig, H. Nishimaru, J. Matsumoto, Y. Takamura, A. Berthoz, T. Ono, H. Nishijo, Rat retrosplenial cortical involvement in wayfinding using visual and locomotor cues. Cereb. Cortex 30, 1985-2004 (2020).

62. T. Macpherson, M. Morita, T. Hikida, Striatal direct and indirect pathways control decision-making behavior. Front. Psychol. 5, 1301 (2014).

63. M. Tsanov, E. Chah, S. D. Vann, R. B. Reilly, J. T. Erichsen, J. P. Aggleton, S. M. O'Mara, Theta-modulated head direction cells in the rat anterior thalamus. J. Neurosci. 31, 9489-9502 (2011).

64. L. L. Chen, L. H. Lin, E. J. Green, C. A. Barnes, B. L. McNaughton, Head-direction cells in the rat posterior cortex. I. Anatomical distribution and behavioral modulation. Exp. Brain Res. 101, 8-23 (1994).

65. A. Saiki, Y. Sakai, R. Fukabori, S. Soma, J. Yoshida, M. Kawabata, H. Yawo, K. Kobayashi, M. Kimura, Y. Isomura, In vivo spiking dynamics of intra- and extratelencephalic projection neurons in rat motor cortex. Cereb. Cortex 28, 1024-1038 (2018).

66. S. B. Floresco, J. K. Seamans, A. G. Phillips, Selective roles for hippocampal, prefrontal cortical, and ventral striatal circuits in radial-arm maze tasks with or without a delay. J. Neurosci. 17, 1880-1890 (1997).

67. A. J. D. Nelson, L. Kinnavane, E. Amin, S. M. O'Mara, J. P. Aggleton, Deconstructing the direct reciprocal hippocampal-anterior thalamic pathways for spatial learning. J. Neurosci. 40, 6978-6990 (2020).

68. N. Tamamaki, Y. Nojyo, Preservation of topography in the connections between the subiculum, field CA1, and the entorhinal cortex in rats. J. Comp. Neurol. 353, 379-390 (1995).

69. M. P. Witter, T. P. Doan, B. Jacobsen, E. S. Nilssen, S. Ohara, Architecture of the entorhina cortex a review of entorhinal anatomy in rodents with some comparative notes. Front. Syst. Neurosci. 11, 46 (2017).

70. A. Fernandez-Ruiz, A. Oliva, G. A. Nagy, A. P. Maurer, A. Berenyi, G. Buzsaki, EntorhinalCA3 dual-input control of spike timing in the hippocampus by theta-gamma coupling. Neuron 93, 1213-1226.e5 (2017).

71. K. Mizuseki, A. Sirota, E. Pastalkova, G. Buzsaki, Theta oscillations provide tempora windows for local circuit computation in the entorhinal-hippocampal loop. Neuron 64, 267-280 (2009).

72. S. S. Deshmukh, D. Yoganarasimha, H. Voicu, J. J. Knierim, Theta modulation in the medial and the lateral entorhinal cortices. J. Neurophysiol. 104, 994-1006 (2010).

73. M. A. van der Meer, A. D. Redish, Theta phase precession in rat ventral striatum links place and reward information. J. Neurosci. 31, 2843-2854 (2011).

74. A. S. Alexander, L. M. Rangel, D. Tingley, D. A. Nitz, Neurophysiological signatures of temporal coordination between retrosplenial cortex and the hippocampal formation. Behav. Neurosci. 132, 453-468 (2018).

75. N. K. Logothetis, O. Eschenko, Y. Murayama, M. Augath, T. Steudel, H. C. Evrard M. Besserve, A. Oeltermann, Hippocampal-cortical interaction during periods of subcortical silence. Nature 491, 547-553 (2012).

76. N. Yamawaki, X. Li, L. Lambot, L. Y. Ren, J. Radulovic, G. M. G. Shepherd, Long-range inhibitory intersection of a retrosplenial thalamocortical circuit by apical tuft-targeting CA1 neurons. Nat. Neurosci. 22, 618-626 (2019).

77. M. Sosa, H. R. Joo, L. M. Frank, Dorsal and ventral hippocampal sharp-wave ripples activate distinct nucleus accumbens networks. Neuron 105, 725-741.e8 (2020).

78. T. Kitanishi, Y. Ikegaya, N. Matsuki, Behaviorally evoked transient reorganization of hippocampal spines. Eur. J. Neurosci. 30, 560-566 (2009).

79. J. Yang, D. H. Kim, J. L. Hendricks, M. Leach, R. Northey, D. C. Martin, Ordered surfactanttemplated poly(3,4-ethylenedioxythiophene) (PEDOT) conducting polymer on microfabricated neural probes. Acta Biomater. 1, 125-136 (2005).

80. S. Fujisawa, A. Amarasingham, M. T. Harrison, G. Buzsaki, Behavior-dependent short-term assembly dynamics in the medial prefrontal cortex. Nat. Neurosci. 11, 823-833 (2008).

81. E. W. Schomburg, A. Fernandez-Ruiz, K. Mizuseki, A. Berenyi, C. A. Anastassiou, C. Koch, G. Buzsaki, Theta phase segregation of input-specific gamma patterns in entorhinalhippocampal networks. Neuron 84, 470-485 (2014).

82. G. Paxinos, C. Watson, The Rat Brain in Stereotaxic Coordinates (Academic, ed. 6, 2006) 
Acknowledgments: We thank T. Fukuda for providing the antibody to NOS, H. Miyawaki for valuable suggestions on the manuscript, and Osaka City University Research Support Platform for allowing our use of a confocal microscope. Funding: This work was supported by JSPS KAKENH (20H03356, 19H05225, 18H05137, 17K19462, 16H04656, and 16H01279 to K.M. and 20K06878, 19H04937, 17H05977, 17H05575, and 17K14939 to T.K.), JST PRESTO (JPMJPR1882 to T.K.) Toray Science Foundation (to K.M.), Takeda Science Foundation (to K.M. and T.K.), The Uehara Memorial Foundation (to K.M. and T.K.), The Naito Foundation (to K.M. and T.K.), The Nakajima Foundation (to T.K.), SEI Group CSR Foundation (to K.M. and T.K.), Life Science Foundation of Japan (to K.M.), Brain Science Foundation (to K.M.), Shimazu Zaidan (to K.M.), Novartis Foundation (Japan) for the Promotion of Science (to K.M.), Osaka City University Strategic Research Grant for young researches (to T.K.), and Osaka City University Strategic Research Grant for basic researches (to K.M.). Author contributions: T.K. and K.M. conceived the project. T.K. performed the experiments and analyzed the data except the retrograde tracing R.U. performed the retrograde tracing and its analysis. T.K. and K.M. wrote the manuscript with input from R.U. Competing interests: The authors declare that they have no competing interests. Data and materials availability: The datasets supporting this study and AAVs generated in this study are available from the corresponding authors upon reasonable request. All data needed to evaluate the conclusions in the paper are present in the paper and/or the Supplementary Materials. Additional data related to this paper may be requested from the authors.

Submitted 9 October 2020

Accepted 25 January 2021

Published 10 March 2021

10.1126/sciadv.abf1913

Citation: T. Kitanishi, R. Umaba, K. Mizuseki, Robust information routing by dorsal subiculum neurons. Sci. Adv. 7, eabf1913 (2021) 


\section{ScienceAdvances}

\section{Robust information routing by dorsal subiculum neurons}

Takuma Kitanishi, Ryoko Umaba and Kenji Mizuseki

Sci Adv 7 (11), eabf1913.

DOI: $10.1126 /$ sciadv.abf1913

ARTICLE TOOLS

SUPPLEMENTARY

MATERIALS

REFERENCES

PERMISSIONS http://advances.sciencemag.org/content/7/11/eabf1913

http://advances.sciencemag.org/content/suppl/2021/03/08/7.11.eabf1913.DC1

This article cites 79 articles, 16 of which you can access for free http://advances.sciencemag.org/content/7/11/eabf1913\#BIBL

http://www.sciencemag.org/help/reprints-and-permissions

Science Advances (ISSN 2375-2548) is published by the American Association for the Advancement of Science, 1200 New York Avenue NW, Washington, DC 20005. The title Science Advances is a registered trademark of AAAS.

Copyright (C) 2021 The Authors, some rights reserved; exclusive licensee American Association for the Advancement of Science. No claim to original U.S. Government Works. Distributed under a Creative Commons Attribution NonCommercial License 4.0 (CC BY-NC). 